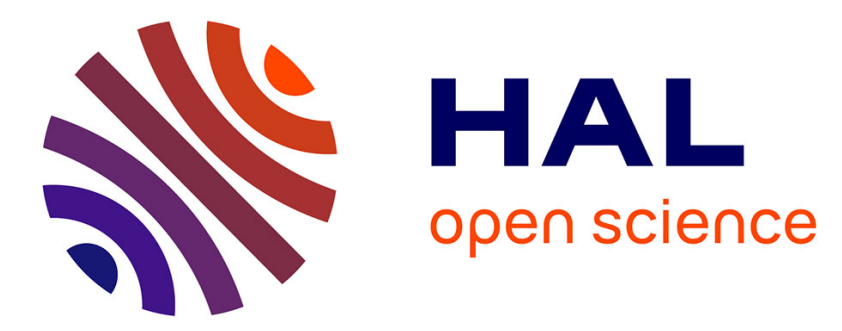

\title{
Tuning down the environmental interests of organoclays for emerging pollutants: Pharmaceuticals in presence of electrolytes
}

Régis Guégan, Tiago de Oliveira, Julien Le Gleuher, Yoshiyuki Sugahara

\section{- To cite this version:}

Régis Guégan, Tiago de Oliveira, Julien Le Gleuher, Yoshiyuki Sugahara. Tuning down the environmental interests of organoclays for emerging pollutants: Pharmaceuticals in presence of electrolytes. Chemosphere, 2020, 239, 124730 (10 p.). 10.1016/j.chemosphere.2019.124730 . insu-02288741

\section{HAL Id: insu-02288741 \\ https://hal-insu.archives-ouvertes.fr/insu-02288741}

Submitted on 16 Sep 2019

HAL is a multi-disciplinary open access archive for the deposit and dissemination of scientific research documents, whether they are published or not. The documents may come from teaching and research institutions in France or abroad, or from public or private research centers.
L'archive ouverte pluridisciplinaire HAL, est destinée au dépôt et à la diffusion de documents scientifiques de niveau recherche, publiés ou non, émanant des établissements d'enseignement et de recherche français ou étrangers, des laboratoires publics ou privés.

\section{(ㅇ)(1) $\$$}

Distributed under a Creative Commons Attribution - NonCommercial - NoDerivatives| 4.0 


\section{Journal Pre-proof}

Tuning down the environmental interests of organoclays for emerging pollutants:

Pharmaceuticals in presence of electrolytes

Régis Guégan, Tiago De Oliveira, Julien Le Gleuher, Yoshiyuki Sugahara

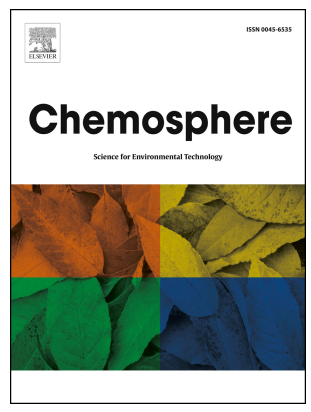

PII:

S0045-6535(19)31960-5

DOI:

https://doi.org/10.1016/j.chemosphere.2019.124730

Reference: CHEM 124730

To appear in: $\quad E C S N$

Received Date: 22 May 2019

Revised Date: 22 August 2019

Accepted Date: 30 August 2019

Please cite this article as: Guégan, Ré., De Oliveira, T., Le Gleuher, J., Sugahara, Y., Tuning down the environmental interests of organoclays for emerging pollutants: Pharmaceuticals in presence of electrolytes, Chemosphere (2019), doi: https://doi.org/10.1016/j.chemosphere.2019.124730.

This is a PDF file of an article that has undergone enhancements after acceptance, such as the addition of a cover page and metadata, and formatting for readability, but it is not yet the definitive version of record. This version will undergo additional copyediting, typesetting and review before it is published in its final form, but we are providing this version to give early visibility of the article. Please note that, during the production process, errors may be discovered which could affect the content, and all legal disclaimers that apply to the journal pertain.

(C) 2019 Published by Elsevier Ltd. 


\title{
1 Tuning down the environmental interests of organoclays for emerging
}

\section{pollutants: pharmaceuticals in presence of electrolytes}

Régis Guégan ${ }^{1,2 *}$, Tiago De Oliveira ${ }^{1}$, Julien Le Gleuher ${ }^{1}$, Yoshiyuki Sugahara ${ }^{2}$

${ }^{1}$ Institut des Sciences de la Terre d'Orléans, UMR 7327, CNRS-Université d'Orléans, 1A Rue de la Férollerie, 45071 Orléans Cedex 2, France

\author{
${ }^{2}$ Faculty of Science and Engineering, (Global Center for Science and Engineering), Waseda \\ University, 3-4-1 Okubo, Shinjuku-ku, Tokyo 169-8555, Japan
}

\section{May $22^{\text {th }}, 2019$}

*To whom correspondence should be addressed. e-mail: regis.guegan@univ-orleans.fr or regis.guegan@aoni.waseda.jp

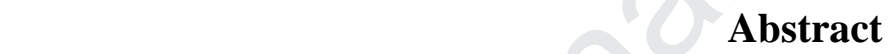

The impact of electrolytes on the adsorption of emerging pollutants: pharmaceuticals onto layered materials: a raw clay mineral and its nonionic and cationic organoclay derivatives was studied. The selected pharmaceuticals: amoxicillin, norfloxacin, sulfamethoxazole, metoprolol, carbamazepine, and trimethoprim show different electric charges: zwitterionic, anionic, cationic and neutral and hydrophobic character (different $\log \mathrm{P}$ ). Without any salts, the set of complementary data obtained by UV and infrared spectroscopies, X-ray diffraction points out the importance of the electric charge which represents a key parameter in both the spontaneity and feasibility of the adsorption. In contrast, the hydrophobicity of the analytes plays a minor role but determines the magnitude of the adsorbed amount of pharmaceuticals onto organoclays. With a dual hydrophilic and hydrophobic behavior, nonionic organoclay appears to be the most polyvalent material for the removal of the pharmaceuticals. In the 
presence of electrolytes $\left(\mathrm{NaCl}\right.$ at a concentration of $\left.1 \times 10^{-2} \mathrm{~mol} \mathrm{~L}^{-1}\right)$, both nonionic and cationic organoclays show a decrease of their efficiencies, whereas the adsorption is particularly enhanced for Na-Mt except for the cationic species (trimethoprim and metoprolol). Thus, in realistic experimental conditions close to those of natural effluents, raw clay mineral appears as the most appropriate sorbent for the studied pharmaceuticals while it raises the question of the usefulness of organoclays in water remediation strategy.

\section{Introduction}

The chemical modification of swelling-type clay minerals, by using surfactants of different nature: cationic, nonionic, zwitterionic to get organoclays, enhances the adsorption efficiency but also extents the range of adsorbed organic molecules (Stockmeyer 1991, Stapleton et al. 1994, Liu and Gonzalez 1999, El-Nahhal and Safi 2004, Groisman et al. 2004, Shen 2004, Gao and Pedersen 2005, Polubesova et al. 2005, Bekçi et al. 2006, Deng et al. 2006, Polubesova et al. 2006, Guégan et al. 2009, Guégan 2010, Sarkar et al. 2010, Zhang et al. 2010, Guégan 2011, Lee et al. 2011, Park et al. 2011, Guegan 2013, Zha et al. 2013, Guégan et al. 2015, Thiebault et al. 2015, De Oliveira and Guégan 2016, De Oliveira et al. 2017, Guégan et al. 2017, De Oliveira et al. 2018). Thus, numerous studies pointed out the interests of organoclays as adsorbents, going as far as to suggest these materials as perennial and realistic solutions for the remediation of wastewater or as tertiary treatment for drinking water (Stockmeyer 1991, Polubesova et al. 2005, Polubesova et al. 2006, Undabeytia et al. 2008). In the latter case, the adsorption displays the main interest to avoid any degradation of the molecules but requires a recycling of the hybrid materials after being in contact with pollutants. The efficient adsorption of diverse organic pollutants: pharmaceuticals, and other phytosanitary products in batch experimental conditions illustrates the interests of cationic organoclays (Alther 2002, Park et al. 2011). Due to their dual hydrophilic-hydrophobic 
behaviors and possible cation exchange capacity, nonionic organoclays represent polyvalent adsorbents towards many organic products (Deng 2003, Guégan et al. 2015, De Oliveira et al. 2018). The previous batch adsorption experiments were conducted under unrealistic conditions (i.e. use of synthetic water without any organic matter or with only monomolecular matrix), quite distant from those in natural effluents. Indeed, in effluents, several antagonistic effects may occur: competition between molecules and organic matter, electrolytes which may tune down the interests of organoclays as adsorbents.

In a natural context, the presence of electrolytes and their fluctuations of concentration may affect the adsorption/desorption equilibrium lead to a release of adsorbed pollutants onto layered materials playing the role of carrier phases for pollutants. Besides the complexity of the whole interaction that may be involved, the impact of ionic strength on the adsorption of both organic and inorganic species can be considered now as being well established for clay minerals (Liu and Gonzalez 1999, Gao and Pedersen 2005, Wang et al. 2009): Electrolytes can act as a screening effect which limits the transfer of the analytes, or enhances the adsorption through ionic bridges. If the effects of the ionic strength for clay minerals are relatively well understood, interestingly, research works focusing on organoclays and organic pollutants including pharmaceuticals appear scarce (Stapleton et al. 1994, El-Nahhal and Safi 2004, Anirudhan and Ramachandran 2006).

Pharmaceutical products are frequently found in large quantities in numerous effluents, with compounds identified as persistent in the natural environment due to their molecular complexity but also possible associations with mineral phases that may preserve them. These molecules of relatively moderate molecular masses show various degrees of freedom and complex molecular behaviors as diverse as their therapeutic actions with hydrophobic features and acid-base properties that modulate their electrical charge with $\mathrm{pH}$. Their presence in the natural environment at concentrations reaching several nanograms is 
recognized to cause adverse effects on many ecosystems and represents a public health matter involving the interests of numerous scientists focusing on the development of novel adsorbents (Adriano et al. 2005, Bekçi et al. 2006, Kim et al. 2010, Liu et al. 2011, Moussavi et al. 2013, Kodešová et al. 2015, De Oliveira and Guégan 2016, Nielsen and Bandosz 2016, De Oliveira et al. 2017, Limousy et al. 2017).

The objective of this study concerns the understanding about the adsorption and possible desorption of diverse pharmaceuticals onto cationic and nonionic organoclays in the presence of electrolytes that mimic the experimental conditions of the natural context. Thus, this research work represents a rupture to the previous studies aiming at characterizing the adsorption of pharmaceuticals onto organoclays in batch situation with synthetic waters where only thermal or kinetic parameters were investigated. To understand the impact of the ionic strength, six pharmaceutical products (PPs) with different features: electric charges (cationic, zwitterionic, nonionic, anionic or neutral products), hydrophobic character with LogP ranging from -1.03 to 2.45 , were adsorbed onto both nonionic and cationic organoclays. The effectiveness of adsorption of PPs onto organoclays was compared to: a sodium exchanged montmorillonite (from Wyoming) via a multi-technique approach including X-ray diffraction, infrared and UV-Visible spectroscopies, providing important insights in the different interactional mechanisms and their evolutions in the presence of electrolytes. 


\section{Materials and techniques}

\subsection{Materials}

The montmorillonite (Mt) used in that study was obtained from the Source Clay Minerals Repository, University of Missouri (Columbia, MO). This clay mineral (from Wyoming) was used as a starting material for organoclay preparation but also as a referenced adsorbent. The structural formula can be expressed as: $\left(\mathrm{Ca}_{0.12} \mathrm{Na}_{0.32} \mathrm{~K}_{0.05}\right)\left[\mathrm{Al}_{3.01} \mathrm{Fe}(\mathrm{III})_{0.41} \mathrm{Mn}_{0.01} \mathrm{Mg}_{0.54} \mathrm{Ti}_{0.02}\right]-$ $\left[\mathrm{Si}_{7,98} \mathrm{Al}_{0.02}\right] \mathrm{O}_{20}(\mathrm{OH})_{4}$. Mt was fractioned below $2 \mu \mathrm{m}$ by gravity sedimentation. Then, the resulting clay mineral was purified and sodium $\left(\mathrm{Na}^{+}\right)$exchanged. This montmorillonite $(\mathrm{Na}-$ Mt) exhibits a cation exchange capacity (CEC) of 93 meq per $100 \mathrm{~g}$ clay.

Polyoxyethylene (20) oleyl ether $\left(\right.$ Brij $\left.^{\circledR}-\mathrm{O} 20\right)$ and Benzyldimethyltetradecylammonium (BDTA) chemicals were supplied from Sigma Aldrich Chemical company. These two chemicals: Brij and BDTA are nonionic and cationic surfactants respectively. Aqueous solutions of surfactants with Millipore deionized water were prepared at a concentration of 1 time the CEC of Mt clay for BDTA, and at about $1.13 \times 10^{-3} \mathrm{~mol}^{-1} \mathrm{~L}^{-1}$ for Brij-O-20. Then, these surfactant solutions were mixed to Mt aqueous dispersions before being stirred at 300 $\mathrm{rpm}$ for $24 \mathrm{~h}$. At the end of this procedure, the solutions were centrifuged at $3000 \mathrm{rpm}$ for 20 min and the supernatants were removed and the solid fractions (organoclays) were recovered. The resulting organoclays were dried at $100^{\circ} \mathrm{C}$ for $24 \mathrm{~h}$ before using them as adsorbents or prior any analyses.

\subsection{Experimental techniques}

The concentration of the six pharmaceutical compounds before and after being in contact with the layered adsorbents: raw clay mineral and organoclays was obtained by UV-Visible analysis using an Evolution 220 spectrophotometer (Thermo Scientific). Fourier transform infrared (FTIR) measurements in the range $650-4000 \mathrm{~cm}^{-1}$, were recorded using a Thermo 
Nicolet 6700 FT spectrometer equipped with a Deuterated Triglycine Sulfate (DTGS) detector and a Nicolet Continuum microscope. The powder samples were spread over a $\mathrm{NaCl}$ window of the microscope. The analyzed sample area was a square of side $100 \mu \mathrm{m}$ chosen under the microscope 15X Infinity Reflechromat objective. The analyses were performed in transmission mode and each spectrum corresponded to the average of 256 scans collected at 2 $\mathrm{cm}^{-1}$ resolution. The $\mathrm{d}_{001}$ spacing's of the layered materials before and after being in contact with the antibiotics were determined by the first $00 \mathrm{l}$ reflection from the X-rays patterns which were recorded in a conventional $\theta-\theta$ Bragg-Brentano configuration by using a Thermo Electron ARL'XTRA diffractometer equipped with a $\mathrm{Cu}$ anode $\left(\mathrm{CuK}_{\alpha}=1.5418 \AA\right)$ coupled with a $\mathrm{Si}(\mathrm{Li})$ solid detector. The diffractograms on dry samples $\left(100^{\circ} \mathrm{C}\right.$ for $\left.24 \mathrm{~h}\right)$ were performed between 1 and $24^{\circ}(2 \theta)$ with an angular and time steps of $0.04^{\circ}$ and $10 \mathrm{~s}$, respectively.

\subsection{Adsorption of PPs}

Amoxocillin (AMX) or 6-(p-hydroxy- $\alpha$-aminophenylacetamido) penicillanic acid), Norfloxacin (NFX) or 1-Ethyl-6-fluoro-1,4-dihydro-4-oxo-7-(1-piperazinyl)-3quinolinecarboxylic acid, Sulfamethoxazole (SMX) or (4-Amino-N-(5-methyl-3-isoxazolyl)) benzenesulfonamide), Trimethoprim (TRI) (5-[(3,4,5-Trimethoxyphenyl)methyl]-2,4pyrimidinediamine), Metoprolol (MTP) or 1-(isopropylamino)-3-[4-(2methoxyethyl)phenoxy]propan-2-ol, and carbamazepine (CBZ) or 5-Carbamoyl-5Hdibenz(b,f)azepine were purchased from Sigma-Aldrich Chemical, and assumed to have a purity $>98 \%$. These products were used in batch adsorption experiments onto raw clay mineral and its nonionic and cationic organoclays derivatives using at least 10 initial aqueous solutions ranging from $10 \mathrm{mg} \mathrm{L}^{-1}$ up to $4 \mathrm{~g} \mathrm{~L}^{-1}$ (for AMX, or below the possible maximum concentration according to the solubility of each pharmaceutical compound). 
AMX displays a LogP of about 0.87 and $2 \mathrm{pK}_{\mathrm{a}}$ couples of 3.23 and 7.43 while NFX show a

LogP of -1.03 and owns $2 \mathrm{pK}_{\mathrm{a}}$ of 5.77 and 8.68 (for strongest acidic and basic form), leading to cationic-zwitterionic-anionic behavior respectively along the $\mathrm{pH}$ range $0-14$ (Table 1 ). In contrast, SMX with a $\operatorname{LogP}$ of 0.89 (solubility in water about $610 \mathrm{mg} \mathrm{L}^{-1}$ at $37^{\circ} \mathrm{C}$ ) shows a $\mathrm{pK}_{\mathrm{a}}$ couple of 6.16 and 1.97 for strongest acidic and basic form respectively, driving to a cationic-neutral-anionic sequence following the $\mathrm{pH}$. TRI shows a $\log \mathrm{P}$ of 1.28 and has a water solubility of $400 \mathrm{mg} \mathrm{L}^{-1}\left(\right.$ at $\left.25^{\circ} \mathrm{C}\right)$ and exhibits a cationic to neutral behavior $\left(\mathrm{pK}_{\mathrm{a}}=7.16\right)$. With a similar water solubility of about $400 \mathrm{mg} \mathrm{L}^{-1}$, MTP displays the same acid base behavior with a cationic to neutral sequence $\left(\mathrm{pK}_{\mathrm{a}}=9.67\right)$ and shows a $\log \mathrm{P}$ of 1.88 . Finally, CBZ has the largest LogP value at about 2.45 among the selected PPs in this study and is neutral (or nonionic hydrophobic compound) on the whole $\mathrm{pH}$ range with a poor solubility in water of about $18 \mathrm{mg} \mathrm{L}^{-1}$. At a $\mathrm{pH}$ value close to that of effluents $(\mathrm{pH}=6.5$ of a study), AMX and NFX are mainly zwitterionic, with a predominance of about 90 and $80 \%$ and anionic (10\%) and cationic (20\%) respectively (checked by chromatography analyses and consolidated by some literature data). SMX shows a neutral-anionic behavior with a ratio of $30 / 70 \%$. TRI is essentially in its cationic form with a frequency of $80 \%$ (20\% other species are in neutral forms) while only MTP cations are present (Table 1).

The solid to liquid ratio was identical with $100 \mathrm{mg}$ of sorbents used for $50 \mathrm{~mL}$ of PPs aqueous solutions in centrifuge tubes. Samples were shaken on a rotary shaker at $50 \mathrm{rpm}$ during $24 \mathrm{~h}$ in order to reach the equilibrium and then centrifuged at $5000 \mathrm{rpm}$ for $25 \mathrm{~min}$. Both supernatants and sorbents after contact with the PPs were removed and analyzed through UVVisible spectroscopy. The effect of the ionic strength was achieved by the addition of $\mathrm{NaCl}$ salts at a concentration of $1.0 \times 10^{-2} \mathrm{~mol} \mathrm{~L}^{-1}$. The amount of adsorbed PPs was calculated by the difference between the initial and equilibrium final concentrations that allowed us to determine the equilibrium adsorption isotherms. Prior XRD and FTIR characterizations, the 
165 entire resulting organoclays and Mt after adsorption of PPs were dried at $100^{\circ} \mathrm{C}$ for $48 \mathrm{~h}$. No

166 release of organic compounds was observed based on prior thermal gravimetry analyses (i.e.

167 organic compounds have large molecular masses with poor volatility and are usually degraded 168 in the temperature range $250-350^{\circ} \mathrm{C}$ ). 
3. Results and discussion

171

172

173

174

175

\subsection{Organoclay Characteristics}

The whole layered materials: BDTA-Mt, Brij 0.4 -Mt organoclays, and Na-Mt were characterized by both XRD and FTIR (supporting data) analyses. As expected, the proper intercalation of the surfactants within the interlayer space of the starting Na-Mt was confirmed by a shift at low angle values $(2 \theta)$ of the $00 l$ reflections. With the introduced concentrations ( 1 time the value of the CEC for the cationic surfactant and a similar amount for the Brij), the expansion of the interlayer space reaches $18.3 \AA$ for both BDTA-Mt and Brij $_{0.4}$-Mt organoclays, corresponding to lateral bilayers organization (Figure 1). FTIR spectra confirm such surfactant organization and show typical features characteristics of the organic compounds, such as the absorption bands at $2840-2920 \mathrm{~cm}^{-1}$ relative to the symmetric and antisymmetric $\mathrm{CH}_{2}$ stretching vibrations of the surfactant alkyl chains, of which frequencies stress out gauche conformation of the molecules (Guégan et al. 2009, Guégan 2010, Guegan 2013, Guegan et al. 2016) (supporting data).

Since the adsorption properties of the organoclays mainly depend on the kind of surfactants used, two different surfactants of different nature (nonionic and cationic) and saturated and unsaturated were used. Thus, the prepared materials display complementary properties: from cation exchange capacity, and hydrophilicity for untreated Na-Mt, dual hydrophilicity/phobicity for Brij $_{0.4}-\mathrm{Mt}$; to hydrophobicity or organophilicity and even possible anion adsorption ability for BDTA-Mt (Guégan et al. 2015, De Oliveira and Guégan 2016, De Oliveira et al. 2017, De Oliveira et al. 2018). In addition, the difference 


\subsection{Interaction mechanisms of the PPs onto layered materials without electrolytes}

196

197

198

199

200

201

202

203

204

205

206

207

208

209

210

211

212

213

214

\subsubsection{Case of cationic species: Metoprolol and Trimethoprim}

The Figure 2 shows the equilibrium adsorption isotherms of the whole pharmaceuticals onto the three sorbents in this study. These isotherms represent the adsorbed amounts of the pharmaceuticals onto the layered materials after being in contact for 24 hours under stirring (batch experiments), as a function of the equilibrium concentration of pharmaceuticals. As expected for cationic compounds that can be ion-exchanged with the inorganic cations located within the interlayer space of untreated or raw swelling clay minerals, the adsorption isotherms onto Na-Mt reveal a Langmuir or L-type line shape, which is well known for adsorption cases (Figure 2) (Bekçi et al. 2006, Guégan et al. 2015, Thiebault et al. 2015, De Oliveira et al. 2018). Interestingly similar behavior can be observed onto both nonionic and cationic organoclays, which thus confirms the proper adsorption of the two cationic pharmaceuticals (metoprolol and trimethoprim) on the three adsorbents. Interestingly, with a similar water solubility value as TRI, the adsorption of metoprolol (MTP) displays a different behavior without any notable saturation for both Na-Mt and Brij $\mathrm{j}_{0.4} \mathrm{Mt}$, whereas it appears rather limited onto BDTA-Mt as it could be expected for cationic species (Guégan et al. 2015, De Oliveira et al. 2018). In the latter case, the adsorbed amount reaches a maximum value of about $1.26 \times 10^{-4} \mathrm{~mol} \mathrm{~g}^{-1}$, in contrast to those of $5.08 \times 10^{-4}$ and $5.62 \times 10^{-4} \mathrm{~mol} \mathrm{~g}^{-1}$ for Brij . $^{-}$ Mt rand Na-Mt respectively. Similar trends about the small affinity of the PPs with BDTA-Mt are reflected with the fitting parameters derived from both the Langmuir and Freundlich models which are minimum. The Freundlich constant $K_{F}$ represents the volume of water that can be treated per gram of material. By using this parameter to list a material adsorption capacity, it is possible to find a similar degree of affinity of both MTP and TRI with the adsorbents: Brij 0.4 -Mt $\left(K_{F}=8.35 \times 10^{-3} \mathrm{Lg}^{-1}\right)>\mathrm{Na}-\mathrm{Mt}\left(K_{F}=4.72 \times 10^{-2} \mathrm{Lg}^{-1}\right)>$ BDTA-Mt (Table 2). 
As expected with organic cations proportion of both TRI and MTP, a limited adsorption onto

BDTA-Mt is observed. For cationic species, the adsorption is mainly driven by electrostatic interaction through cation exchange with the inorganic cations $\left(\mathrm{Na}^{+}\right)$in the case of $\mathrm{Na}-\mathrm{Mt}$ and Brij $_{0.4}$-Mt (Bekçi et al. 2006, Guégan et al. 2015, Thiebault et al. 2015, De Oliveira et al. 2018). In BDTA-Mt, such cation exchange is no more possible due to the presence of cationic surfactant within the interlayer space. Despite the lack of any electrostatic interaction, the organophilic character of both adsorbent (BDTA-Mt) and the analytes (here MTP and TRI), contributes to a favorable adsorption, as the parameter $1 / \mathrm{n}$ comprised between 0.1 and 1 underlines (Kodešová et al. 2015). With 20\% of neutral-species for TRI, the repulsion forces are reduced by enhancing the transfer of mass of organic species. For both Na-Mt and Brij $\mathrm{j}_{0.4^{-}}$ Mt materials (for which the whole inorganic cations are presumed to be accessible), the main driving force for adsorption involves electrostatic interaction with cation exchanges between $\mathrm{Na}^{+}$and amine moieties of TRI and MTP (Bekçi et al. 2006). Additionally, due to the presence of a hydrophobic environment and the versatility of the material with a dual hydrophobic/hydrophilic behavior, Brij 0.4 -Mt offers supplementary adsorption sites leading to an increase of the adsorption of TRI in contrast to Na-Mt, and their intercalation within the interlayer space of the whole layered materials. This intercalation cannot be observed for organoclays where the intercalated surfactants already increased an interlayer space. In contrast, the intercalation with similar amount of adsorbed PPs could be highlighted in Na-Mt, with an extension of the phyllosilicate galleries reaching about 15.5 and $14.7 \AA$ for TRI and MTP respectively, comparatively to that of Na-Mt: 9.6 A (Figure 3).

\subsubsection{Adsorption of zwitterionic species: case of the Amoxicillin and Nofloxacin}

Amoxicillin (AMX) shows a great affinity to the whole adsorbents with an adsorption at large amount $\left(5.68 \times 10^{-3} \mathrm{~mol} \mathrm{~g}^{-1}\right)$ onto the whole layered materials, with a bold affinity of AMX 
for BDTA-Mt. By using $K_{F}$ (Table 2 and Figure $2 \mathrm{n}$ and $q_{\max }$ ), the affinity of AMX is as follows: BDTA-Mt $>$ Brij $_{0.4}-\mathrm{Mt}>\mathrm{Na}-\mathrm{Mt}$. The slight excess of $\mathrm{BDTA}^{+}$combined with their hydrophobic character favor the adsorption of AMX with its $\mathrm{CO}_{2}^{-}$moieties through electrostatic and hydrophobic interactions (Adriano et al. 2005, Putra et al. 2009, Belhachemi and Djelaila 2017). In contrast, AMX can be cation exchanged in Na-Mt, leading to its intercalation with an increase of the interlayer spacing to nearly $15 \AA$ in agreement with a molecular size of AMX, driving to an adsorbed amount larger than the value of the CEC (9.29 x $10^{-4} \mathrm{~mol} \mathrm{~g}^{-1}$ ) (Figure 3). This suggests that additional forces such as ion-dipole and even hydrophobic interaction contribute also in the adsorption in a second step but in a lesser extent. Similar mechanisms can be found in Brij $\mathrm{j}_{0.4}$-Mt with a larger adsorption of PP due to the hydrophobic nature of the organo-layered material.

Norfloxacin (NFX) displays a great affinity to Na-Mt with an adsorbed amount close to the CEC: $8.48 \times 10^{-4} \mathrm{molg}^{-1}$ and a $K_{F}$ of $7.80 \times 10^{-2} \mathrm{~L} \mathrm{~g}^{-1}$. Indeed, at a $\mathrm{pH}=6.5, \mathrm{NFX}$ shows $17 \%$ cationic and $83 \%$ zwitterionic species, driving to possible substitution of $\mathrm{Na}^{+}$cations in both Na-Mt and Brij $0_{0.4}$-Mt. However, in the latter case, the presence of a nonionic surfactant may restrict the proper diffusion and ion-exchange to occur, diminishing in that way the number of accessible $\mathrm{Na}^{+}$to be exchanged. The adsorbed amount of NFX onto Brij ${ }_{0.4}-\mathrm{Mt}$ at about $4.24 \mathrm{x}$ $10^{-4} \mathrm{~mol} \mathrm{~g}^{-1}$ represents half the value of the CEC, suggesting that $50 \%$ of the exchangeable inorganic cations can be mobilized in the adsorption of NFX, and thus leads to a lower $K_{F}$ (in comparison to that of Na-Mt) of $5.66 \times 10^{-2} \mathrm{~L} \mathrm{~g}^{-1}$. With an adsorbed amount of only $2.39 \times 10^{-}$ ${ }^{4} \mathrm{molg}^{-1}$, the adsorption onto BDTA-Mt appears rather low. This trend is also confirmed with the parameter derived from Freundlich equation. Such low affinity of NFX to a cationic organoclay is nevertheless normal due to (i) the repulsive forces between analyte and BDTAMt, (ii) the limitation to perform any ion-exchange and (iii) the hydrophilic nature of NFX ( $\log \mathrm{P}=-1.03)$. However, as a zwitterionic compound, NFX displays also some negative 
charges that may be responsible of its adsorption onto BDTA-Mt. Indeed, for organoclays prepared at concentration above 1 CEC with additional, surfactant can be organized in paraffin structure with a wide expansion making it easier the intercalation of organic compounds and even anionic species.

With the observation of additional bands related to those of the pharmaceuticals, FTIR technique confirms proper the adsorption of NFX onto layered materials onto layered materials (Figure 4). Additionally, this technique can give new insights in the moieties of the molecules in interaction with the layered materials as it could be discussed in previous research works (Guégan et al. 2015, De Oliveira and Guégan 2016, De Oliveira et al. 2017). The integrated intensity of the absorption bands characteristics of the NFX in the reduced spectral range between 1270 and $1570 \mathrm{~cm}^{-1}$ related to the modes of elongation of $\mathrm{CO}$ of the ester and acid functions allows one to follow the evolution of the adsorption with an analysis onto a solid as it could be possible with adsorption isotherms determined through UV spectroscopy with difference of concentrations in liquid samples. The resulting evolution of the integrated intensities of the vibration bands of NFX shows similar trends as the adsorption isotherms highlighted with a better affinity of NFX to Na-Mt $>$ Brij $_{0.4}-\mathrm{Mt}>\mathrm{BDTA}-\mathrm{Mt}$ (Figure 5).

\subsubsection{Adsorption of a neutral or nonionic hydrophobic compound: case of the}

\section{Carbamazepine}

CBZ shows a limited solubility in water $\left(18 \mathrm{mg} \mathrm{L}^{-1}\right)$ due to its hydrophobic character and may be one of the main reasons about its persistence in numerous effluents. Thus, the adsorbed amount of this pharmaceutical onto the whole layered materials appears quite low, one order of magnitude lower than the other studied PPs in this study. Nevertheless, the resulting adsorption isotherms at the equilibrium point out the affinity of CBZ for the whole adsorbents 
which is enhanced for BDTA-Mt $>$ Brij $_{0.4}-\mathrm{Mt}$ and Na-Mt with a maximum adsorbed amount reaching about $2.53 \times 10^{-5}, 1.18 \times 10^{-5}$ and $4.14 \times 10^{-6} \mathrm{~mol} \mathrm{~g}^{-1}$ respectively. As expected, the hydrophobic character of CBZ limits the transfer of mass onto Na-Mt while the hydrophobic environment in the organoclays allows its proper adsorption.

Besides being nonionic and hydrophobic compound, CBZ can be weakly ionizable and holds punctual partial electric charge allowing possible physisorption processes that could be responsible for an adsorption (Zhang et al. 2010, Kodešová et al. 2015). Thus, CBZ may be sorbed onto Na-Mt through possible hydrogen bonds with the surface silanol groups (located in the edges of the phyllosilicate sheets in very small amounts) and for both organoclays with weak molecular hydrophobic interaction in addition with possible $\pi-\pi$ interactions in the case of BDTA-Mt explaining the large adsorbed amount in the latter case.

\subsubsection{Adsorption of an anionic compound: the sulfamethoxazole}

The adsorption of sulfamethoxazole (SMX) is effective for the three materials as the adsorption isotherms revealed with a gradual growth of the adsorbed amount as the concentration is increased without reaching any plateau (Figure 2). The affinity of SMX is particularly enhanced for BDTA-Mt $>$ Brijo.4-Mt $>$ Na-Mt as both $\mathrm{q}_{\mathrm{m}}$ and $\mathrm{K}_{\mathrm{F}}$ stressed out (Table 2). At a $\mathrm{pH}$ of 6.5 , SMX is mainly anionic (67\%) and neutral (33\%). Thus, as expected, the adsorption of this pharmaceutical onto Na-Mt is considerably limited. However, neutral SMX can be totally adsorbed through probable ion-dipole interaction, leading to its intercalation besides its hydrophobic character, as it could be observed by X-ray diffraction data (Figure 3). Indeed, $\mathrm{q}_{\mathrm{m}}$ reaches $2.56 \times 10^{-4} \mathrm{~mol} \mathrm{~g}^{-1}$ onto Na-Mt which matches with a deviation of only $4 \%$ of the amount of SMX in its neutral form. However, the existence of negative charge at the surface of $\mathrm{Na}-\mathrm{Mt}$ associated to weak polarizability of SMX considerably prevents further adsorption due to repulsive effects (Gao and Pedersen 2005). 
Indeed, the deprotonated form of sulfamethoxazole significantly decreases the ability of the sulfonamide group of sulfamethoxazole to be able to perform $\pi$ - $\pi$ interactions with the $\pi$ donor functions of the materials (Chen et al. 2014). In Brijo.4-Mt, the introduction of surfactant shields these repulsive forces while introducing a hydrophobic environment, leading to an adsorption in a larger proportion than Na-Mt. Thus, neutral SMX can be adsorbed onto the nonionic organoclay through accessible inorganic $\mathrm{Na}^{+}$cations, while the hydrophobic environment due to the presence of surfactant, allows a lager adsorption of the other species. With similar hydrophobic environment combined with a slight excess of $\mathrm{BDTA}^{+}, \mathrm{SMX}$ is adsorbed in large amount with deprotonated moieties $(\pi-\pi$ electron donoracceptor interaction), and also hydrophobic-type molecular interactions (Rostamian and Behnejad 2016).

\subsection{Impact of the ionic strengths on the adsorption of organoclays to PPs}

Besides not being the most efficient sorbent, the adsorption efficiency of the layered materials in this study reasonably appears quite suitable for pharmaceuticals. However, depending on the nature of the organic pollutants, their adsorption capacities that can be similar to activated carbons. The experiments were essentially performed in synthetic water without any change of electrolytes. In a natural context, effluents show diverse electrolytes at different concentrations that may significantly perturb the magnitude of the adsorption or lead to a possible desorption. Thus, as described previously, the main driving force for the adsorption of pharmaceuticals results from electrostatic interactions, which are known to be sensitive to any change of the ionic strengths with usually the observation of an increase of the adsorbed amount (Gao and Pedersen 2005, Bekçi et al. 2006).

As it was expected, the ionic strength plays on the magnitude of the adsorption of the whole pharmaceuticals. Both line shapes and evolution of the isotherms follow the same trend as before but, except metoprolol the values of the maximum adsorbed amount of 
pharmaceuticals as well as the parameters derived from the fitting procedure and more particularly $K_{F}$ which appears affected with a change of the experimental conditions (Figure 2 and Table 2). However, both nonionic and cationic organoclays show a decrease of their efficiencies, in contrast to Na-Mt for which the adsorption is particularly enhanced except for the cationic species (TRI and MTP) and thus appears as the most appropriate sorbent for the studied pharmaceuticals in the presence of $\mathrm{NaCl}$ at a concentration of $1 \times 10^{-2} \mathrm{~mol} \mathrm{~L}^{-1}$.

For the cationic species (TMP and TRI), the addition of electrolytes reduces the total adsorption capacity of the three materials. For TRI, a decrease in the adsorbed quantities of about $8.4 \%, 34.2 \%$ and $25.1 \%$ can be observed whereas for MTP, it reaches a variation of 8.0\%, $1.6 \%$ and $15.7 \%$ for Na-Mt, BDTA-Mt and Brij ${ }_{0.4}-\mathrm{Mt}$ respectively. By focusing on $K_{F}$, the same trend is confirmed. As expected for BDTA-Mt, organic cations are poorly adsorbed and can be mainly adsorbed through hydrophobic interaction and it is verified in the case of MTP where the $\mathrm{NaCl}$ salts do not affect the adsorbed amount, nor $K_{F}$. It is interesting to observe how the speciation of the organic compounds plays again on the adsorption. With the presence of an electrolyte, the transfer of nonionic TRI is considerably reduced and explains why the decrease of the adsorbed amount onto BDTA-Mt. Indeed, the presence of $\mathrm{Na}^{+}$cations may shield the sites of adsorption and induces a competition effect which does not favor the sorption of neutral species to cationic organoclay. Moreover, $\mathrm{Na}^{+}$ions are known to perturb electron-acceptor $\pi$ - $\pi$-electron interactions and may explain also the decrease of TRI onto BDTA-Mt. For sorbents where exchange of cations process is possible (i.e. Na-Mt and Brijo.4Mt) $\mathrm{Na}^{+}$ions in solution compete to other organic cations, here the pharmaceuticals and thus limits the adsorption. An intercalation of $\mathrm{Na}^{+}$was confirmed by atomic absorption spectroscopy (not shown) and also observed through X-ray diffraction patterns (Figure 3), with a shift to large $2 \theta$ angle values of the 001 reflection where the interlayer space decreases 
369

370

371

372

373

374

375

376

377

from 15.01 to $14.48 \AA$ and from 14.66 to $14.23 \AA$ for both TRI and MTP respectively after the addition of salts.

With $q_{\max }$ amount and $K_{F}$ as main parameters to appreciate the affinity between analytes to sorbents, the presence of $\mathrm{NaCl}$ does induce any large change in the sequence of affinity of both AMX and NFX with the layered materials (Figure 2 and Table 2). However, the presence of the electrolytes reduces the transfer of the pharmaceuticals onto organoclays with a decrease of the adsorbed amounts for AMX of about $25 \%$ and $27 \%$ and for NFX by $49 \%$ and $70 \%$ for both BDTA-Mt and Brijo.4-Mt respectively. In contrast, Na-Mt shows a clear improvement of the adsorption capacities in the presence of $\mathrm{NaCl}$. Indeed, the maximum adsorbed amounts are $2.69 \times 10^{-3}$ and $9.91 \times 10^{-4} \mathrm{molg}^{-1}$ for AMX and NFX respectively representing an increase of $190 \%$ and $17 \%$. The study of the solid phase by FTIR of Na-Mt also brings a confirmation of the improvement of the adsorption in the presence of electrolyte and confirms the general trends observed with the isotherms (Figures 4-5).

The addition of salts may change the solubility and hydrophobicity of substances in solution that can reduce the adsorption capacity of adsorbents (Anirudhan and Ramachandran 2006, Bui and Choi 2010). A loss of hydrophobicity could indeed penalize the interactions of the similar range of energy involved in the adsorption of pharmaceuticals to organoclays. Electrolytes in solution may also combine with pharmaceuticals and reduce considerably their diffusion at a surface of the layered materials. The grafting of surfactant onto the surface of the layered materials acting as a brush may prevent a possible diffusion within the interlayer space of the pharmaceuticals or probably the presence of salts aside the organoclays shield the possibility of adsorption of zwitterionic compounds (Figure 6) (Vinu et al. 2006).

The presence of $\mathrm{NaCl}$ that amplifies the polarizability of the molecules via ionic bridges and thus causes a drop-in of the hydrophobicity (Anirudhan and Ramachandran 2006) is likely to explain the change of affinity between CBZ and Na-Mt. The addition of salts does affect the 
main driving force (hydrophobic interaction) for the adsorption of $\mathrm{CBZ}$ to organoclays allowing one to obtain similar adsorbed amounts. However, the possibility to interact through ionic bridges to Na-Mt enhances considerably the adsorption capacity showing an ability to adsorb CBZ at even larger extent than organoclays (Figure 2). Similarly, Na-Mt represents the best suitable material for anionic compounds in presence of electrolytes, where the adsorbed amounts show an increase by reaching $170 \%$ to reach $7.01 \times 10^{-4} \mathrm{~mol} \mathrm{~g}^{-1}$. The addition of salts must change the state of charge of SMX with the possible formation of ion complexes of which nature is different from the surface properties of organoclays and therefore limit its mass transfer. This combination of sodium ions with the deprotonated groups of the molecules leads to the establishment of repulsive forces in regards to the cationic organoclay and decreases its adsorption capacity. Such ion-molecule complexations may explain an improvement in the adsorption in the opposite case of initially repulsive interactions which can be extended to the results obtained for Na-Mt.

\section{Conclusions}

With a study of six pharmaceuticals showing diverse chemical nature (zwitterionic, anionic, cationic and neutrals as well as displaying different hydrophobicity) onto layered materials based on clay minerals with diverse properties (cation exchange, organophilicity, anion adsorption ability) without any electrolytes, electrostatic interactions appear to be the main adsorption mechanisms while hydrophobic parameter plays a second role. However, this latter feature is important since the intercalation of surfactant drives to an organic environment with novel adsorption sites, thus improving the adsorption of pharmaceuticals.

As expected with adsorption mechanisms that bear on electrostatic interactions, the ionic strength strongly affects the adsorption processes of pharmaceuticals with a drastic reduction of the efficiency of both cationic and nonionic organoclays. Such decrease results from (i) a competition effect between salts and the organophilic surface of organoclays to the 
pharmaceuticals, and (ii) a noticeable change in the properties of the aqueous solution that may decrease the hydrophobic character of organic compounds. In contrast, the improvement of the adsorption properties of Na-Mt in the presence of electrolytes can be explained by electric double layers or Debye model and the screening of the electrostatic repulsions with the introduction counter-ions at a surface of the phyllosilicate sheets. Indeed, with monovalent salts, the Debye screening length is quite reduced and decreases the magnitude of the repulsion relative to the van der Waals attraction. This phenomenon obviously favors the adsorption of organic compounds onto $\mathrm{Na}-\mathrm{Mt}$, where ion-dipole interaction through the presence of counter-ions located at the surface of the phyllosilicate sheets. In organoclays, the presence of surfactant already reduces the repulsion forces between the inorganic sheets but generates a hydrophobic environment with the grafting of an organic layer or brush. This combination contributes to the improvement of the adsorption efficiency of organoclays without any electrolytes. However, with salts, their adsorption abilities for pharmaceuticals remain identical or appear considerably reduced. In Na-Mt, salts are located to a surface which lessen the Debye screening length. In contrast, for organoclays the introduced ions remain in solution and may interact with organic compounds, leading to a backward shift of the desorption/adsorption equilibrium. This can go farer since the adsorption of organic compounds to a clay mineral generates step by step a hybrid material, equivalent to organoclays obtained with surfactants, of which efficiency is decreased. Worse, it can drive to the desorption of the adsorbed organic compounds as we could observed (not shown here) and thus raises the question of the usefulness of organoclays in water remediation strategy.

\section{Acknowledgements}

The authors would like to thank the Région Centre Val de Loire (Project MONITOPOL2017 - 00117247) for their financial support. 
Adriano, W. S., V. Veredas, C. C. Santana and L. R. B. Gonçalves (2005). "Adsorption of amoxicillin on chitosan beads: Kinetics, equilibrium and validation of finite bath models." Biochemical Engineering Journal 27(2): 132-137.

Alther, G. (2002). "Using organoclays to enhance carbon filtration." Waste Management 22(5): 507513.

Anirudhan, T. S. and M. Ramachandran (2006). "Adsorptive removal of tannin from aqueous solutions by cationic surfactant-modified bentonite clay." Journal of Colloid and Interface Science 299(1): 116-124.

Bekçi, Z., Y. Seki and M. K. Yurdakoç (2006). "Equilibrium studies for trimethoprim adsorption on montmorillonite KSF." Journal of Hazardous Materials 133(1): 233-242.

Belhachemi, M. and S. Djelaila (2017). "Removal of Amoxicillin Antibiotic from Aqueous Solutions by Date Pits Activated Carbons." Environmental Processes 4(3): 549-561.

Bui, T. X. and H. Choi (2010). "Influence of ionic strength, anions, cations, and natural organic matter on the adsorption of pharmaceuticals to silica." Chemosphere 80(7): 681-686.

Chen, H., B. Gao and H. Li (2014). "Functionalization, pH, and ionic strength influenced sorption of sulfamethoxazole on graphene." Journal of Environmental Chemical Engineering 2(1): 310-315. De Oliveira, T., E. Fernandez, L. Fougère, E. Destandau, M. Boussafir, M. Sohmiya, Y. Sugahara and R. Guégan (2018). "Competitive Association of Antibiotics with a Clay Mineral and Organoclay Derivatives as a Control of Their Lifetimes in the Environment." ACS Omega 3(11): 15332-15342. De Oliveira, T. and R. Guégan (2016). "Coupled Organoclay/Micelle Action for the Adsorption of Diclofenac." Environmental Science \& Technology 50(18): 10209-10215.

De Oliveira, T., R. Guégan, T. Thiebault, C. L. Milbeau, F. Muller, V. Teixeira, M. Giovanela and M. Boussafir (2017). "Adsorption of diclofenac onto organoclays: Effects of surfactant and environmental ( $\mathrm{pH}$ and temperature) conditions." Journal of Hazardous Materials 323: 558-566.

Deng, Y. D., J.B. Dixon, White, G.N. (2003). "Intercalation and surface modification of smectite by two non-ionic surfactants." Clays and Clay Minerals 51: 150-161.

Deng , Y. D., J. B. Dixon, G. N. White (2006). " Bonding mechanisms and conformation of poly(ethylene oxide)-based surfactants in interlayer of smectite." Colloid and Polymer Science 284: 347-356.

El-Nahhal, Y. Z. and J. M. Safi (2004). "Adsorption of phenanthrene on organoclays from distilled and saline water." Journal of Colloid and Interface Science 269(2): 265-273.

Gao, J. and J. A. Pedersen (2005). "Adsorption of Sulfonamide Antimicrobial Agents to Clay Minerals." Environmental Science \& Technology 39(24): 9509-9516.

Groisman, L., C. Rav-Acha, Z. Gerstl and U. Mingelgrin (2004). "Sorption of organic compounds of varying hydrophobicities from water and industrial wastewater by long- and short-chain organoclays." Applied Clay Science 24(3,Äi4): 159-166.

Guegan, R. (2013). "Self-assembly of a non-ionic surfactant onto a clay mineral for the preparation of hybrid layered materials." Soft Matter 9(45): 10913-10920.

Guégan, R. (2010). "Intercalation of a Nonionic Surfactant (C10E3) Bilayer into a Na-Montmorillonite Clay." Langmuir 26(24): 19175-19180.

Guégan, R. (2011). "Confinement effects on water structure in membrane lyotropic phases." Journal of Colloid and Interface Science 358(2): 485-490.

Guégan, R., M. Gautier, J.-M. Beny and F. Muller (2009). "ADSORPTION OF A C10E3 NON-IONIC SURFACTANT ON A Ca-SMECTITE." Clays and Clay Minerals 57(4): 502-509.

Guégan, R., M. Giovanela, F. Warmont and M. Motelica-Heino (2015). "Nonionic organoclay: A 'Swiss Army knife' for the adsorption of organic micro-pollutants?" Journal of Colloid and Interface Science 437: 71-79. 
Guegan, R., K. Sueyoshi, S. Anraku, S. Yamamoto and N. Miyamoto (2016). "Sandwich organization of non-ionic surfactant liquid crystalline phases as induced by large inorganic K4Nb6O17 nanosheets." Chemical Communications 52(8): 1594-1597.

Guégan, R., E. Veron, L. Le Forestier, M. Ogawa and S. Cadars (2017). "Structure and Dynamics of Nonionic Surfactant Aggregates in Layered Materials." Langmuir 33(38): 9759-9771.

Kim, S. H., H. K. Shon and H. H. Ngo (2010). "Adsorption characteristics of antibiotics trimethoprim on powdered and granular activated carbon." Journal of Industrial and Engineering Chemistry 16(3): 344-349.

Kodešová, R., R. Grabic, M. Kočárek, A. Klement, O. Golovko, M. Fér, A. Nikodem and O. Jakšík (2015). "Pharmaceuticals' sorptions relative to properties of thirteen different soils." Science of The Total Environment 511: 435-443.

Lee, Y.-C., W.-K. Park and J.-W. Yang (2011). "Removal of anionic metals by amino-organoclay for water treatment." Journal of Hazardous Materials 190(1): 652-658.

Limousy, L., I. Ghouma, A. Ouederni and M. Jeguirim (2017). "Amoxicillin removal from aqueous solution using activated carbon prepared by chemical activation of olive stone." Environmental Science and Pollution Research 24(11): 9993-10004.

Liu, A. and R. D. Gonzalez (1999). "Adsorption/Desorption in a System Consisting of Humic Acid, Heavy Metals, and Clay Minerals." Journal of Colloid and Interface Science 218(1): 225-232.

Liu, W., J. Zhang, C. Zhang and L. Ren (2011). "Sorption of norfloxacin by lotus stalk-based activated carbon and iron-doped activated alumina: Mechanisms, isotherms and kinetics." Chemical Engineering Journal 171(2): 431-438.

Moussavi, G., A. Alahabadi, K. Yaghmaeian and M. Eskandari (2013). "Preparation, characterization and adsorption potential of the $\mathrm{NH} 4 \mathrm{Cl}$-induced activated carbon for the removal of amoxicillin antibiotic from water." Chemical Engineering Journal 217: 119-128.

Nielsen, L. and T. J. Bandosz (2016). "Analysis of the competitive adsorption of pharmaceuticals on waste derived materials." Chemical Engineering Journal 287: 139-147.

Park, Y., G. A. Ayoko and R. L. Frost (2011). "Application of organoclays for the adsorption of recalcitrant organic molecules from aqueous media." Journal of Colloid and Interface Science 354(1): 292-305.

Polubesova, T., S. Nir, D. Zadaka, O. Rabinovitz, C. Serban, L. Groisman and B. Rubin (2005). "Water Purification from Organic Pollutants by Optimized Micelle-Clay Systems." Environmental Science \& Technology 39(7): 2343-2348.

Polubesova, T., D. Zadaka, L. Groisman and S. Nir (2006). "Water remediation by micelle-clay system: Case study for tetracycline and sulfonamide antibiotics." Water Research 40(12): 2369-2374.

Putra, E. K., R. Pranowo, J. Sunarso, N. Indraswati and S. Ismadji (2009). "Performance of activated carbon and bentonite for adsorption of amoxicillin from wastewater: Mechanisms, isotherms and kinetics." Water Research 43(9): 2419-2430.

Rostamian, R. and H. Behnejad (2016). "A comparative adsorption study of sulfamethoxazole onto graphene and graphene oxide nanosheets through equilibrium, kinetic and thermodynamic modeling." Process Safety and Environmental Protection 102: 20-29.

Sarkar, B., Y. Xi, M. Megharaj, G. S. R. Krishnamurti, D. Rajarathnam and R. Naidu (2010).

"Remediation of hexavalent chromium through adsorption by bentonite based $\operatorname{Arquad}^{\circledR} 2 \mathrm{HT}-75$ organoclays." Journal of Hazardous Materials 183(1): 87-97.

Shen, Y.-H. (2004). "Phenol sorption by organoclays having different charge characteristics." Colloids and Surfaces A: Physicochemical and Engineering Aspects 232(2): 143-149.

Stapleton, M. G., D. L. Sparks and S. K. Dentel (1994). "Sorption of Pentachlorophenol to HDTMA-Clay as a Function of Ionic Strength and pH." Environmental Science \& Technology 28(13): 2330-2335. Stockmeyer, M. R. (1991). "Adsorption of organic compounds on organophilic bentonites." Applied Clay Science 6(1): 39-57.

Thiebault, T., R. Guégan and M. Boussafir (2015). "Adsorption mechanisms of emerging micropollutants with a clay mineral: Case of tramadol and doxepine pharmaceutical products." Journal of Colloid and Interface Science 453: 1-8. 
545 Undabeytia, T., S. Nir, T. Sánchez-Verdejo, J. Villaverde, C. Maqueda and E. Morillo (2008). "A clay546 vesicle system for water purification from organic pollutants." Water Research 42(4-5): 1211-1219.

547 Vinu, A., K. Z. Hossain, G. Satish Kumar and K. Ariga (2006). "Adsorption of I-histidine over

548 mesoporous carbon molecular sieves." Carbon 44(3): 530-536.

549 Wang, S., J. Hu, J. Li and Y. Dong (2009). "Influence of pH, soil humic/fulvic acid, ionic strength,

550 foreign ions and addition sequences on adsorption of $\mathrm{Pb}$ (II) onto GMZ bentonite." Journal of

551 Hazardous Materials 167(1): 44-51.

552 Zha, S. X., Y. Zhou, X. Jin and Z. Chen (2013). "The removal of amoxicillin from wastewater using

553 organobentonite." Journal of Environmental Management 129: 569-576.

554 Zhang, W., Y. Ding, S. A. Boyd, B. J. Teppen and H. Li (2010). "Sorption and desorption of

555 carbamazepine from water by smectite clays." Chemosphere 81(7): 954-960.

556

557 
559 Table 1: Characteristics of the pharmaceutical products used in this study: solubility, pKa, $560 \log P$ and speciation. $\log P$ corresponds to the value of the hydrophobic character of the 561 compounds (a LogP equals to zero corresponds to a compound with an equilibrated balance 562 between its hydrophobic and hydrophilic moieties, while a Log $\mathrm{P}$ negative and positive 563 represents a hydrophilic and hydrophobic compound). The red, green, blue and association of 564 blue and red circles symbolizes the electric charge of the pharmaceuticals at a $\mathrm{pH}=6.5$ : 565 positive, neutral, negative and zwitterion respectively.

$\begin{aligned} & \text { Pharmaceutical } \\ & \text { products }\end{aligned}$
$\begin{aligned} & \text { Norfloxacin } \\ & \text { (NFX) }\end{aligned}$
$\begin{gathered}\text { Amoxicillin } \\ \text { (AMX) }\end{gathered}$


Table 2: Adsorption isotherm constants determined with Langmuir, Freundlich model fits for the adsorption of the whole pharmaceuticals: Amoxicillin (AMX), Sulfamethoxazole (SMX), Trimethoprim (TRI), Metoprolol (MTP), Norfloxacin (NFX) and Carbamazepine (CBZ) onto untreated $\mathrm{Na}$ exchanged montmorillonite: Na-Mt, BDTA-Mt and Brij ${ }_{0.4}-\mathrm{Mt}$ with and without salts $\left(\mathrm{NaCl}\right.$ at a concentration of $\left.1 \mathrm{~mol} \mathrm{~L}^{-1}\right)$.

\begin{tabular}{|c|c|c|c|c|c|c|c|c|}
\hline \multirow[t]{2}{*}{ Adsorbant } & \multirow[t]{2}{*}{ Analytes } & \multicolumn{4}{|c|}{ Langmuir } & \multicolumn{3}{|c|}{ Freundlich } \\
\hline & & $\begin{array}{c}\mathrm{q}_{\max } \\
\left(\mathrm{mol} \cdot \mathrm{g}^{-1}\right)\end{array}$ & $\begin{array}{c}\mathrm{K}_{\mathrm{L}} \\
\left(\mathrm{L} \mathrm{mol}^{-1}\right)\end{array}$ & $\begin{array}{c}\Delta \mathrm{G}^{\circ} \\
\left(\mathrm{kJ} \cdot \mathrm{mol}^{-1}\right)\end{array}$ & $\mathrm{r}^{2}$ & $\begin{array}{c}\mathrm{K}_{\mathrm{F}} \\
\left(\mathrm{L} \cdot \mathrm{g}^{-1}\right)\end{array}$ & $1 / \mathrm{n}$ & $\mathrm{r}^{2}$ \\
\hline \multirow[t]{2}{*}{ Na-Mt } & AMX & $9.29 \times 10^{-4}$ & $9.73 \times 10^{1}$ & -11.72 & 0.988 & $4.71 \times 10^{-2}$ & 0.94 & 0.984 \\
\hline & $\mathrm{AMX}+\mathrm{NaCl}$ & $2.69 \times 10^{-3}$ & $9.98 \times 10^{1}$ & -11.79 & 0.984 & $1.60 \times 10^{-1}$ & 0.95 & 0.966 \\
\hline \multirow[t]{2}{*}{ BDTA-Mt } & AMX & $5.68 \times 10^{-3}$ & $1.46 \times 10^{2}$ & -12.76 & 0.972 & $2.07 \times 10^{-1}$ & 0.81 & 0.983 \\
\hline & $\mathrm{AMX}+\mathrm{NaCl}$ & $4.28 \times 10^{-3}$ & $1.15 \times 10^{2}$ & -12.15 & 0.994 & $1.87 \times 10^{-1}$ & 0.87 & 0.992 \\
\hline \multirow[t]{2}{*}{ Brij $_{0.4}-\mathrm{Mt}$} & AMX & $4.44 \times 10^{-3}$ & $1.31 \times 10^{2}$ & -12.48 & 0.996 & $2.04 \times 10^{-1}$ & 0.88 & 0.997 \\
\hline & $\mathrm{AMX}+\mathrm{NaCl}$ & $3.23 \times 10^{-3}$ & $1.02 \times 10^{2}$ & -11.85 & 0.993 & $1.79 \times 10^{-1}$ & 0.94 & 0.991 \\
\hline \multirow[t]{2}{*}{ Na-Mt } & SMX & $2.56 \times 10^{-4}$ & $4.87 \times 10^{2}$ & -15.85 & 0.967 & $1.24 \times 10^{-2}$ & 0.73 & 0.964 \\
\hline & $\mathrm{SMX}+\mathrm{NaCl}$ & $7.01 \times 10^{-4}$ & $3.30 \times 10^{3}$ & -20.75 & 0.988 & $3.18 \times 10^{-2}$ & 0.57 & 0.957 \\
\hline \multirow[t]{2}{*}{ BDTA-Mt } & SMX & $9.73 \times 10^{-4}$ & $4.78 \times 10^{3}$ & -21.69 & 0.976 & $4.55 \times 10^{-2}$ & 0.59 & 0.961 \\
\hline & $\mathrm{SMX}+\mathrm{NaCl}$ & $6.98 \times 10^{-4}$ & $1.63 \times 10^{3}$ & -18.95 & 0.958 & $2.88 \times 10^{-2}$ & 0.58 & 0.991 \\
\hline \multirow[t]{2}{*}{ Brij $_{0.4}-\mathrm{Mt}$} & SMX & $6.97 \times 10^{-4}$ & $5.06 \times 10^{2}$ & -15.95 & 0.976 & $2.43 \times 10^{-2}$ & 0.66 & 0.930 \\
\hline & $\mathrm{SMX}+\mathrm{NaCl}$ & $3.21 \times 10^{-4}$ & $4.90 \times 10^{2}$ & -15.87 & 0.989 & $2.06 \times 10^{-2}$ & 0.77 & 0.986 \\
\hline \multirow[t]{2}{*}{ Na-Mt } & TRI & $3.80 \times 10^{-4}$ & $5.98 \times 10^{3}$ & -22.27 & 0.982 & $3.44 \times 10^{-3}$ & 0.33 & 0.901 \\
\hline & $\mathrm{TRI}+\mathrm{NaCl}$ & $3.48 \times 10^{-4}$ & $5.15 \times 10^{3}$ & -21.89 & 0.998 & $2.92 \times 10^{-3}$ & 0.33 & 0.899 \\
\hline \multirow[t]{2}{*}{ BDTA-Mt } & TRI & $2.78 \times 10^{-4}$ & $4.46 \times 10^{3}$ & -21.52 & 0.922 & $2.79 \times 10^{-3}$ & 0.36 & 0.907 \\
\hline & $\mathrm{TRI}+\mathrm{NaCl}$ & $1.83 \times 10^{-4}$ & $6.76 \times 10^{2}$ & -16.69 & 0.995 & $2.47 \times 10^{-3}$ & 0.51 & 0.999 \\
\hline \multirow[t]{2}{*}{ Brij $_{0.4}-\mathrm{Mt}$} & TRI & $4.13 \times 10^{-4}$ & $7.59 \times 10^{4}$ & -28.78 & 0.928 & $8.35 \times 10^{-3}$ & 0.40 & 0.996 \\
\hline & $\mathrm{TRI}+\mathrm{NaCl}$ & $3.61 \times 10^{-4}$ & $5.20 \times 10^{3}$ & -21.92 & 0.992 & $3.15 \times 10^{-3}$ & 0.34 & 0.997 \\
\hline \multirow[t]{2}{*}{ Na-Mt } & NFX & $8.48 \times 10^{-4}$ & $4.54 \times 10^{3}$ & -21.57 & 0.984 & $7.80 \times 10^{-2}$ & 0.62 & 0.997 \\
\hline & $\mathrm{NFX}+\mathrm{NaCl}$ & $9.91 \times 10^{-4}$ & $4.96 \times 10^{3}$ & -21.79 & 0.983 & $8.96 \times 10^{-2}$ & 0.61 & 0.988 \\
\hline \multirow[t]{2}{*}{ BDTA-Mt } & NFX & $2.39 \times 10^{-4}$ & $9.53 \times 10^{2}$ & -17.57 & 0.980 & $9.74 \times 10^{-3}$ & 0.64 & 0.975 \\
\hline & $\mathrm{NFX}+\mathrm{NaCl}$ & $1.23 \times 10^{-4}$ & $5.33 \times 10^{2}$ & -16.08 & 0.998 & $2.64 \times 10^{-3}$ & 0.61 & 0.994 \\
\hline \multirow[t]{2}{*}{ Brij $_{0.4}-\mathrm{Mt}$} & NFX & $4.24 \times 10^{-4}$ & $4.42 \times 10^{3}$ & -21.50 & 0.958 & $5.66 \times 10^{-2}$ & 0.66 & 0.977 \\
\hline & $\mathrm{NFX}+\mathrm{NaCl}$ & $1.26 \times 10^{-4}$ & $6.47 \times 10^{2}$ & -16.58 & 0.840 & $6.27 \times 10^{-3}$ & 0.73 & 0.864 \\
\hline \multirow[t]{2}{*}{ Na-Mt } & CBZ & $4.14 \times 10^{-6}$ & $5.63 \times 10^{4}$ & -28.02 & 0.873 & $2.26 \times 10^{-3}$ & 0.65 & 0.972 \\
\hline & $\mathrm{CBZ}+\mathrm{NaCl}$ & $2.54 \times 10^{-5}$ & $1.80 \times 10^{5}$ & -30.99 & 0.976 & $3.22 \times 10^{-2}$ & 0.66 & 0.975 \\
\hline \multirow[t]{2}{*}{ BDTA-Mt } & $\mathrm{CBZ}$ & $2.53 \times 10^{-5}$ & $1.41 \times 10^{5}$ & -30.38 & 0.977 & $2.75 \times 10^{-3}$ & 0.67 & 0.943 \\
\hline & $\mathrm{CBZ}+\mathrm{NaCl}$ & $2.33 \times 10^{-5}$ & $1.34 \times 10^{5}$ & -30.24 & 0.984 & $2.26 \times 10^{-2}$ & 0.66 & 0.985 \\
\hline
\end{tabular}




\section{Journal Pre-proof}

\begin{tabular}{cccccccccc} 
Brij $_{0.4}-\mathrm{Mt}$ & $\mathrm{CBZ}$ & $1.18 \times 10^{-5}$ & $1.10 \times 10^{5}$ & -29.76 & 0.966 & $2.49 \times 10^{-3}$ & 0.54 & 0.939 \\
& $\mathrm{CBZ}+\mathrm{NaCl}$ & $1.99 \times 10^{-5}$ & $1.24 \times 10^{5}$ & -30.05 & 0.981 & $6.11 \times 10^{-3}$ & 0.56 & 0.981 \\
\hline $\mathrm{Na}-\mathrm{Mt}$ & $\mathrm{MTP}$ & $5.62 \times 10^{-4}$ & $3.07 \times 10^{3}$ & -20.57 & 0.967 & $4.72 \times 10^{-2}$ & 0.65 & 0.936 \\
& $\mathrm{MTP}+\mathrm{NaCl}$ & $5.17 \times 10^{-4}$ & $2.98 \times 10^{3}$ & -20.50 & 0.978 & $3.04 \times 10^{-2}$ & 0.61 & 0.905 \\
\multirow{2}{*}{ BDTA-Mt } & $\mathrm{MTP}$ & $1.26 \times 10^{-4}$ & $1.63 \times 10^{3}$ & -18.95 & 0.964 & $3.47 \times 10^{-3}$ & 0.55 & 0.988 \\
& $\mathrm{MTP}+\mathrm{NaCl}$ & $1.24 \times 10^{-4}$ & $1.32 \times 10^{3}$ & -18.41 & 0.879 & $1.52 \times 10^{-3}$ & 0.46 & 0.923 \\
Brij $_{0.4}-\mathrm{Mt}$ & $\mathrm{MTP}$ & $5.08 \times 10^{-4}$ & $1.95 \times 10^{3}$ & -19.40 & 0.974 & $2.91 \times 10^{-2}$ & 0.63 & 0.960 \\
& $\mathrm{MTP}+\mathrm{NaCl}$ & $4.28 \times 10^{-4}$ & $1.68 \times 10^{3}$ & -19.02 & 0.962 & $2.85 \times 10^{-2}$ & 0.66 & 0.900 \\
& & & & & & & & &
\end{tabular}




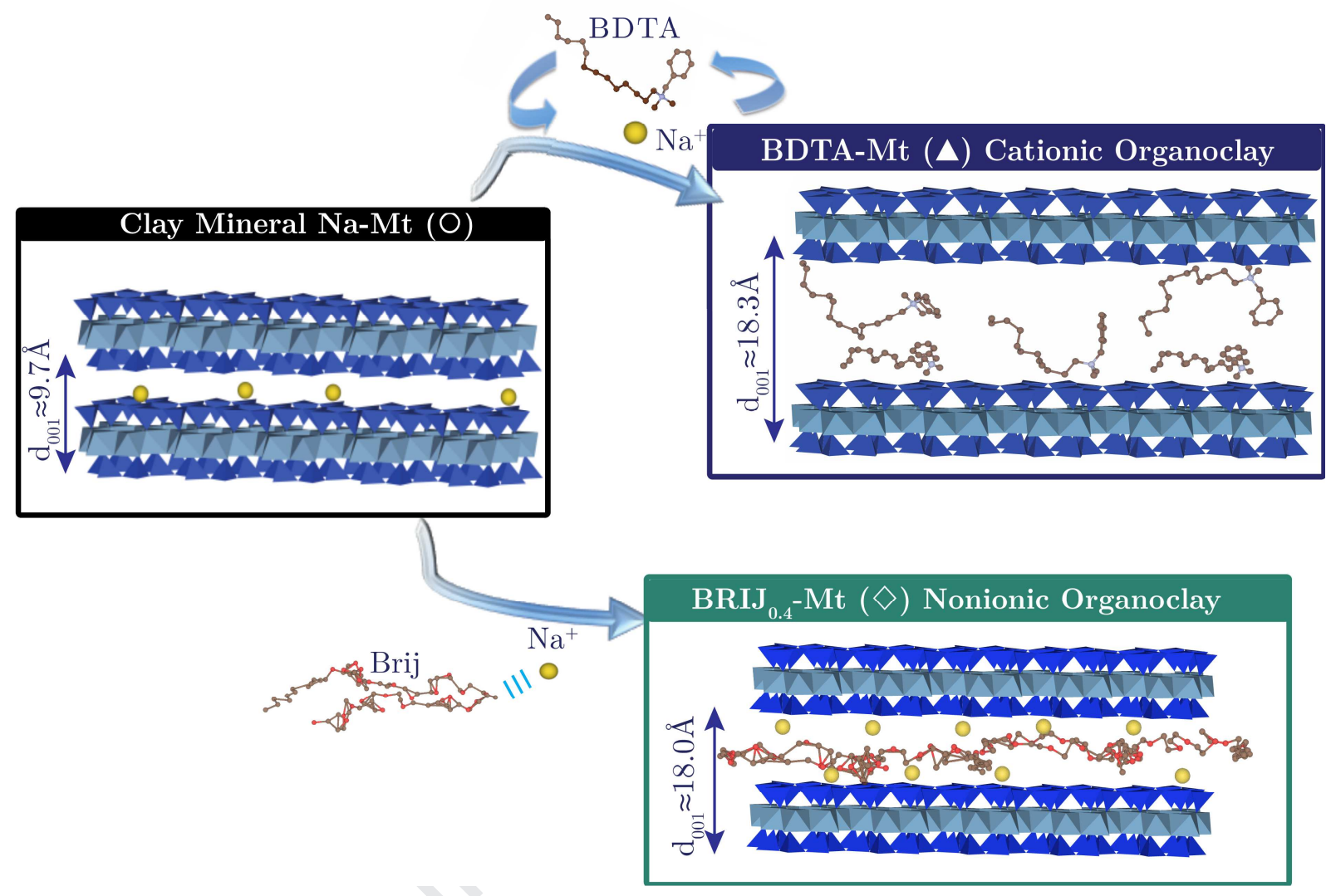

Figure 1: Schematic representation of the whole geo-sorbents used in this study: Na-Mt clay mineral, BDTA-Mt (100\% of the compensations cations are substituted toBDTA through cation exchange) and Brijo.4-Mt, a nonionic organoclay (where the inorganic cations are kept within the interlayer space and Brij is intercalated involving ion-dipole interaction) showing lateral bilayers organization. The sorbents used in this study display singular adsorption properties: hydrophobicity/philicity, cation/anion retention which will be highlighted with six pharmaceuticals ofdifferent chemical nature. 


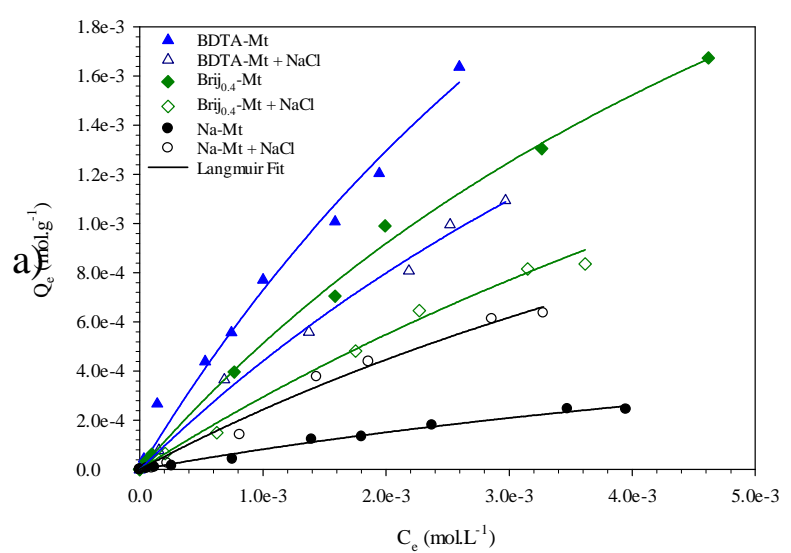

c)

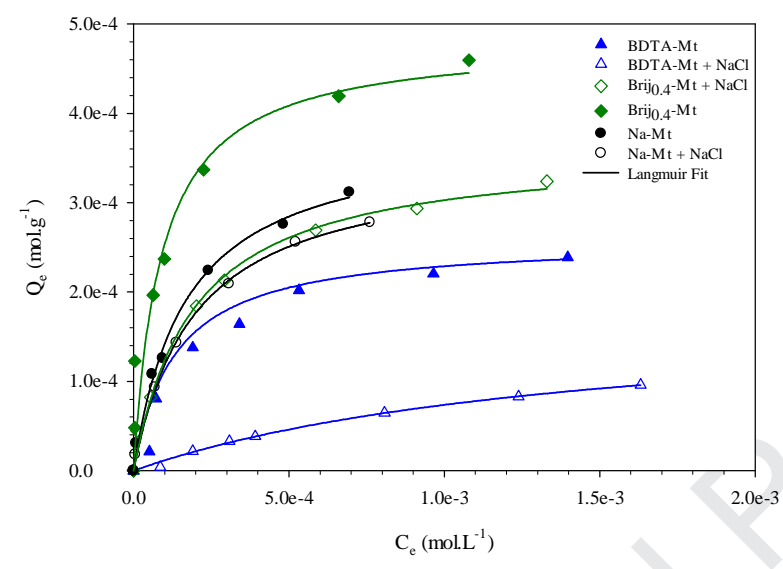

e)

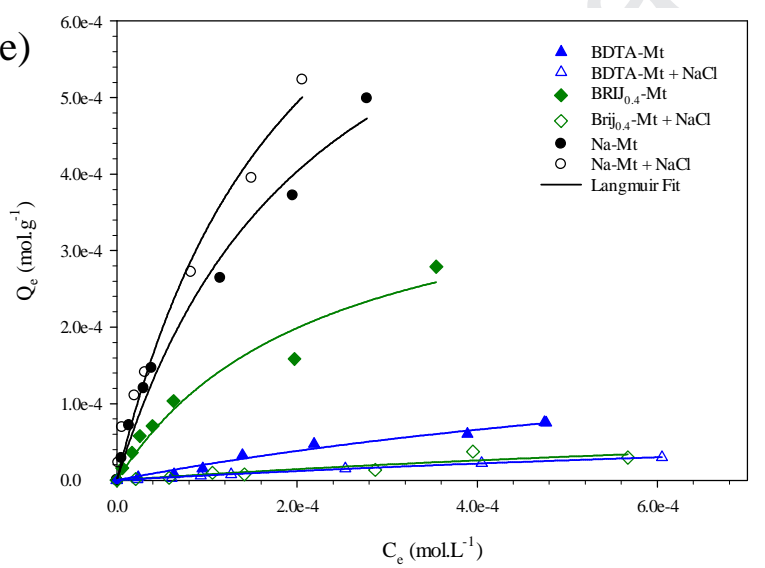

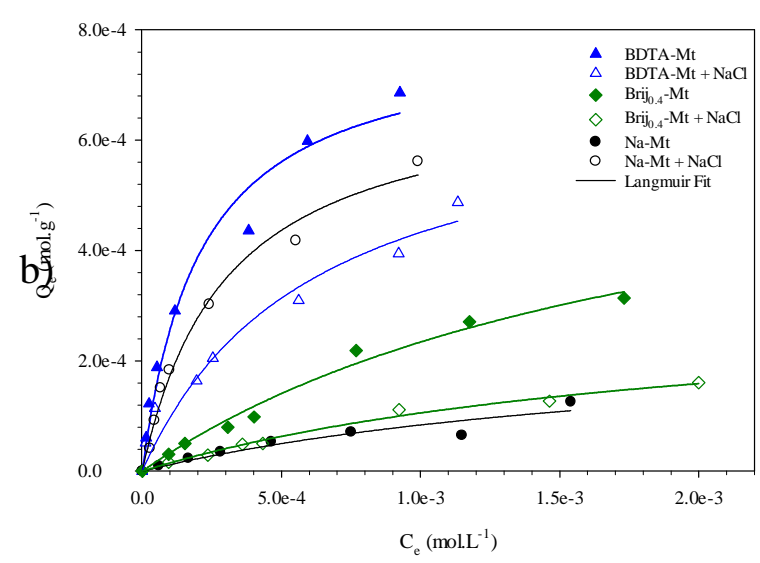

d)

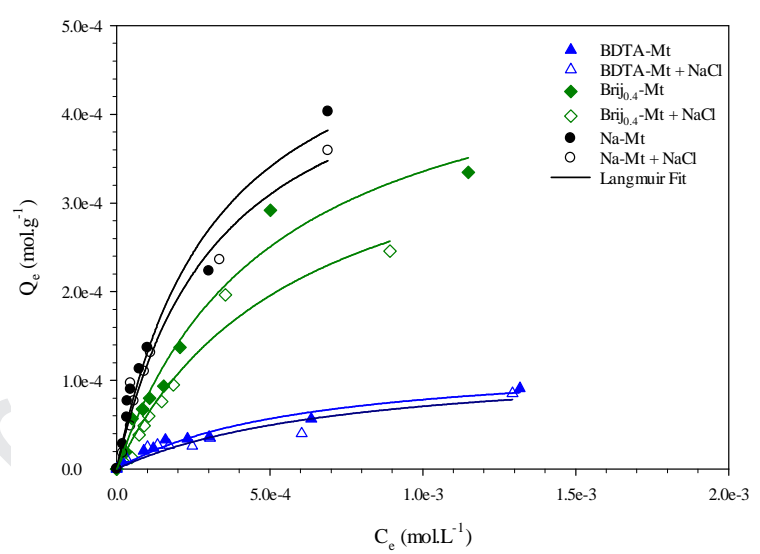

f)

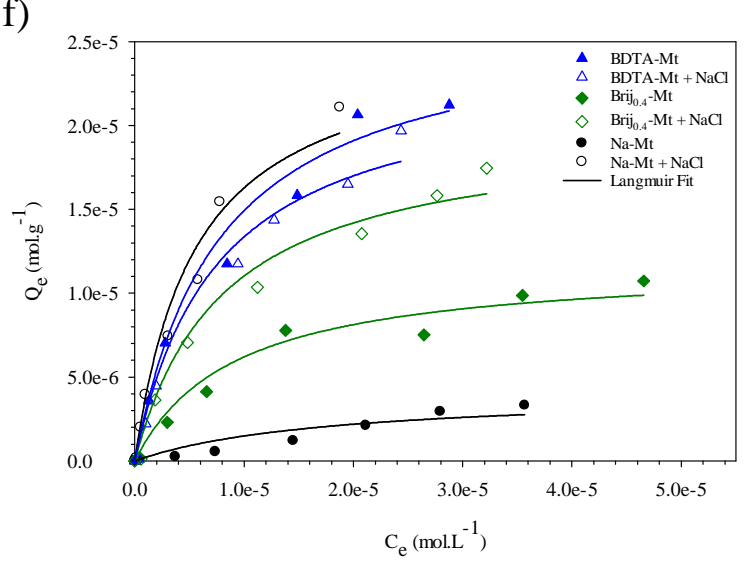

Figure 2: Effect of the ionic strength with the addition of $\mathrm{NaCl}$ electrolytes $\left(10^{-2} \mathrm{M}\right)$ on the equilibrium adsorption isotherms of a) Amoxicillin (AMX), b) Sulfamethoxazole (SMX), c) Trimethoprim (TRI), d) Metoprolol (MTP), e) Norfloxacin (NFX) and f) Carbamazepine (CBZ) onto untreated $\mathrm{Na}$ exchanged montmorillonite: Na-Mt (circle), BDTA-Mt (triangle top) and Brijo.4-Mt (diamond). $\mathrm{Q}_{\mathrm{e}}$ represents the adsorbed amount of pharmaceutical while $\mathrm{C}_{\mathrm{e}}$ is the equilibrium pharmaceutical concentration. The solid lines represent the fits by using the Langmuir equation model. 


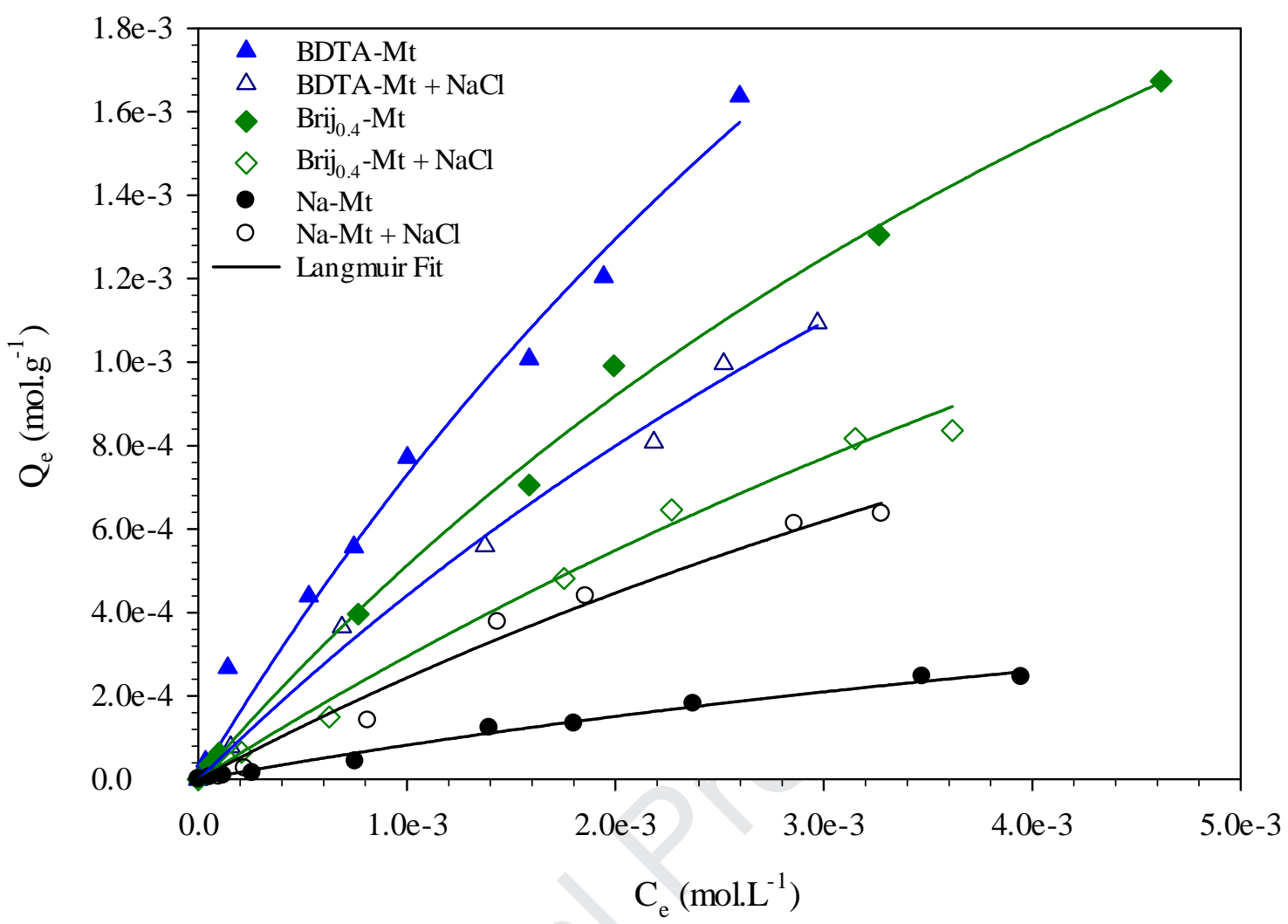

Figure 2a: Effect of the ionic strength with the addition of $\mathrm{NaCl}$ electrolytes $\left(10^{-2} \mathrm{M}\right)$ on the equilibrium adsorption isotherms of Amoxicillin (AMX) onto untreated $\mathrm{Na}$ exchanged montmorillonite: Na-Mt (circle), BDTA-Mt (triangle top) and Brij0.4-Mt (diamond). $\mathrm{Q}_{\mathrm{e}}$ represents the adsorbed amount of pharmaceutical while $\mathrm{C}_{\mathrm{e}}$ is the equilibrium pharmaceutical concentration. The solid lines represent the fits by using the Langmuir equation model. 


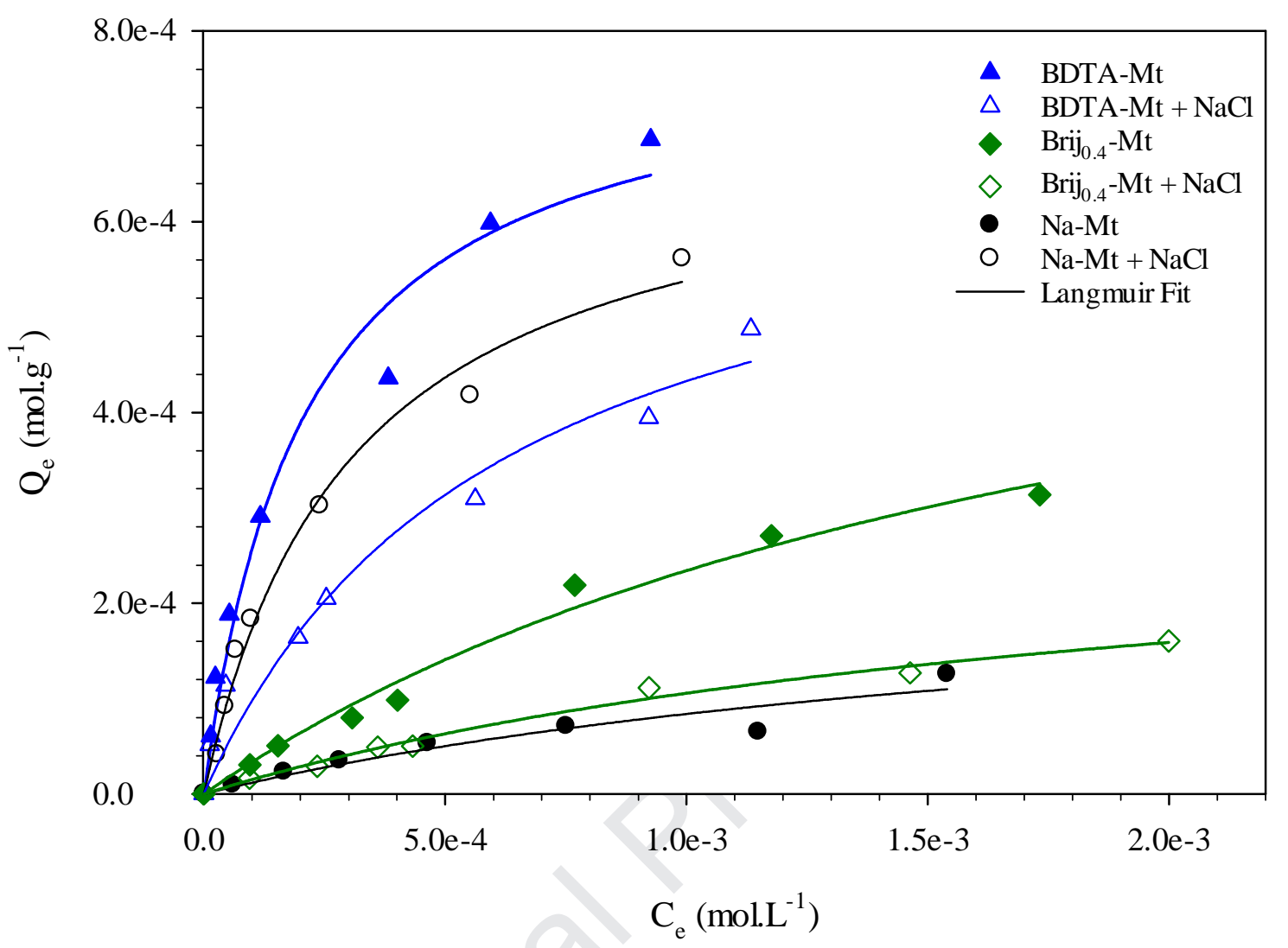

Figure 2b: Effect of the ionic strength with the addition of $\mathrm{NaCl}$ electrolytes $\left(10^{-2} \mathrm{M}\right)$ on the equilibrium adsorption isotherms of Sulfamethoxazole (SMX) onto untreated $\mathrm{Na}$ exchanged montmorillonite: Na-Mt (circle), BDTA-Mt (triangle top) and Brijo.4-Mt (diamond). $\mathrm{Q}_{\mathrm{e}}$ represents the adsorbed amount of pharmaceutical while $\mathrm{C}_{\mathrm{e}}$ is the equilibrium pharmaceutical concentration. The solid lines represent the fits by using the Langmuir equation model. 


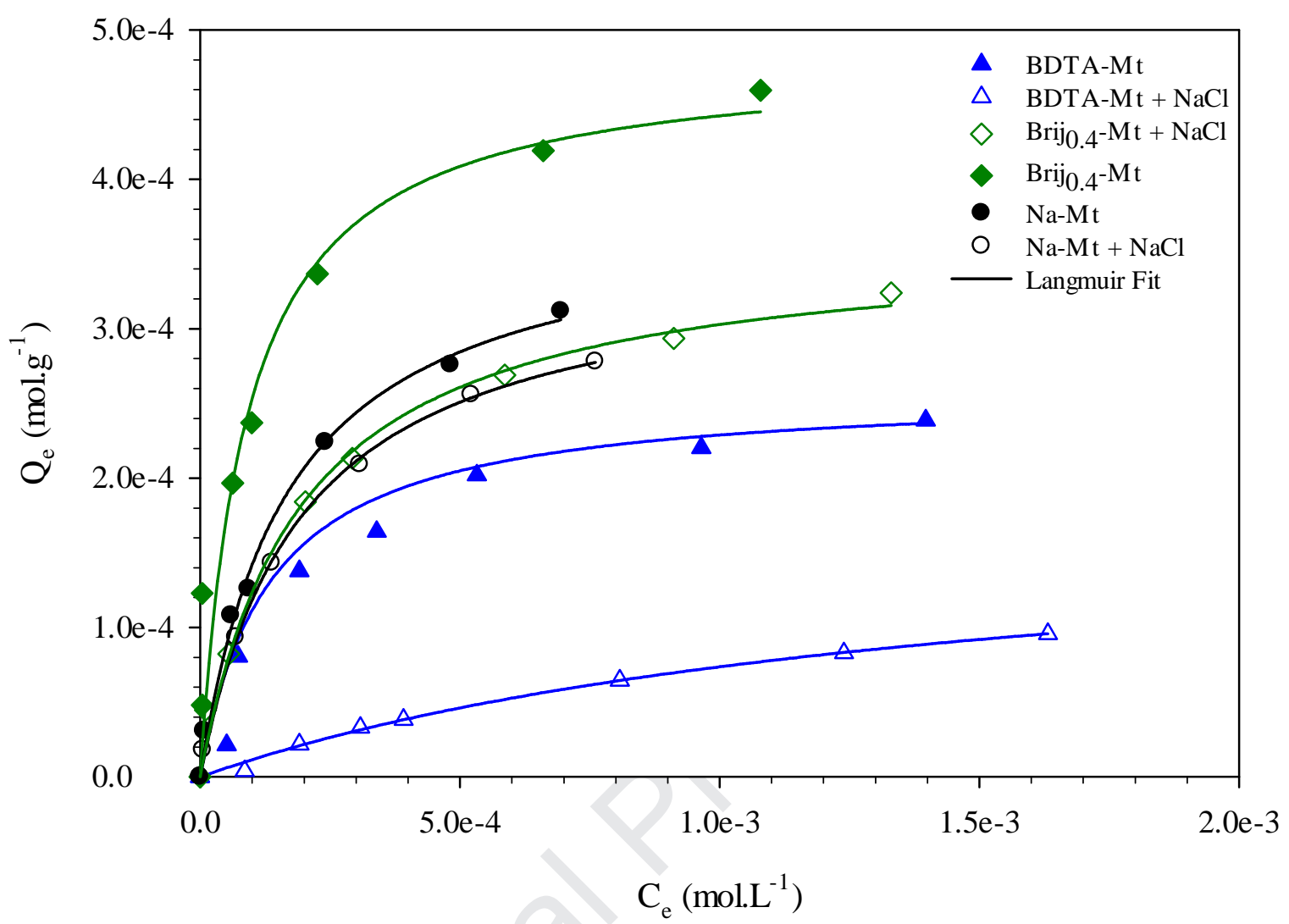

Figure 2c: Effect of the ionic strength with the addition of $\mathrm{NaCl}$ electrolytes $\left(10^{-2} \mathrm{M}\right)$ on the equilibrium adsorption isotherms of Trimethoprim (TRI) onto untreated $\mathrm{Na}$ exchanged montmorillonite: Na-Mt (circle), BDTA-Mt (triangle top) and Brijo.4-Mt (diamond). $\mathrm{Q}_{\mathrm{e}}$ represents the adsorbed amount of pharmaceutical while $\mathrm{C}_{\mathrm{e}}$ is the equilibrium pharmaceutical concentration. The solid lines represent the fits by using the Langmuir equation model. 


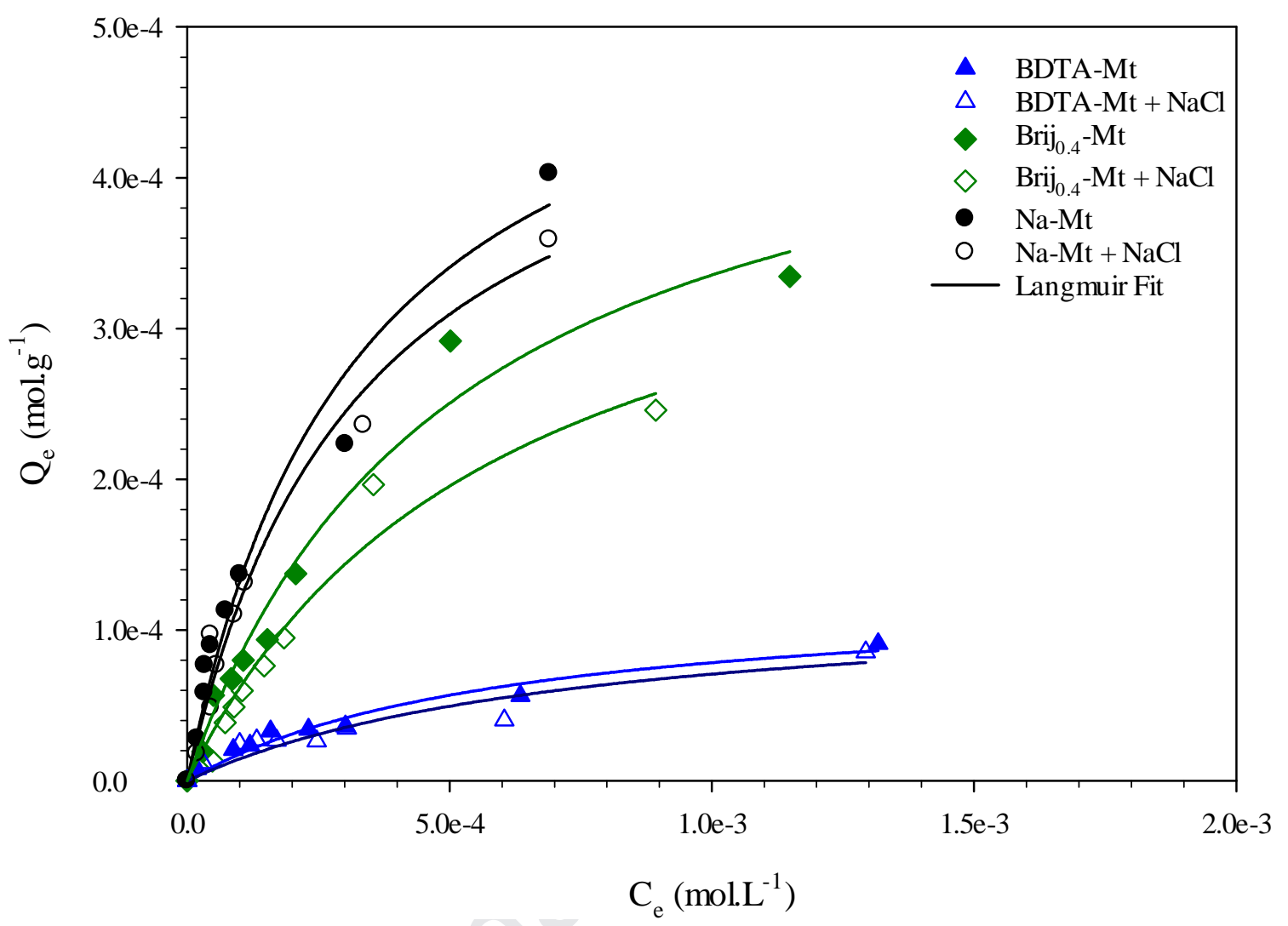

Figure 2d: Effect of the ionic strength with the addition of $\mathrm{NaCl}$ electrolytes $\left(10^{-2} \mathrm{M}\right)$ on the equilibrium adsorption isotherms of Metoprolol (MTP) onto untreated $\mathrm{Na}$ exchanged montmorillonite: Na-Mt (circle), BDTA-Mt (triangle top) and Brij0.4-Mt (diamond). $\mathrm{Q}_{\mathrm{e}}$ represents the adsorbed amount of pharmaceutical while $\mathrm{C}_{\mathrm{e}}$ is the equilibrium pharmaceutical concentration. The solid lines represent the fits by using the Langmuir equation model. 


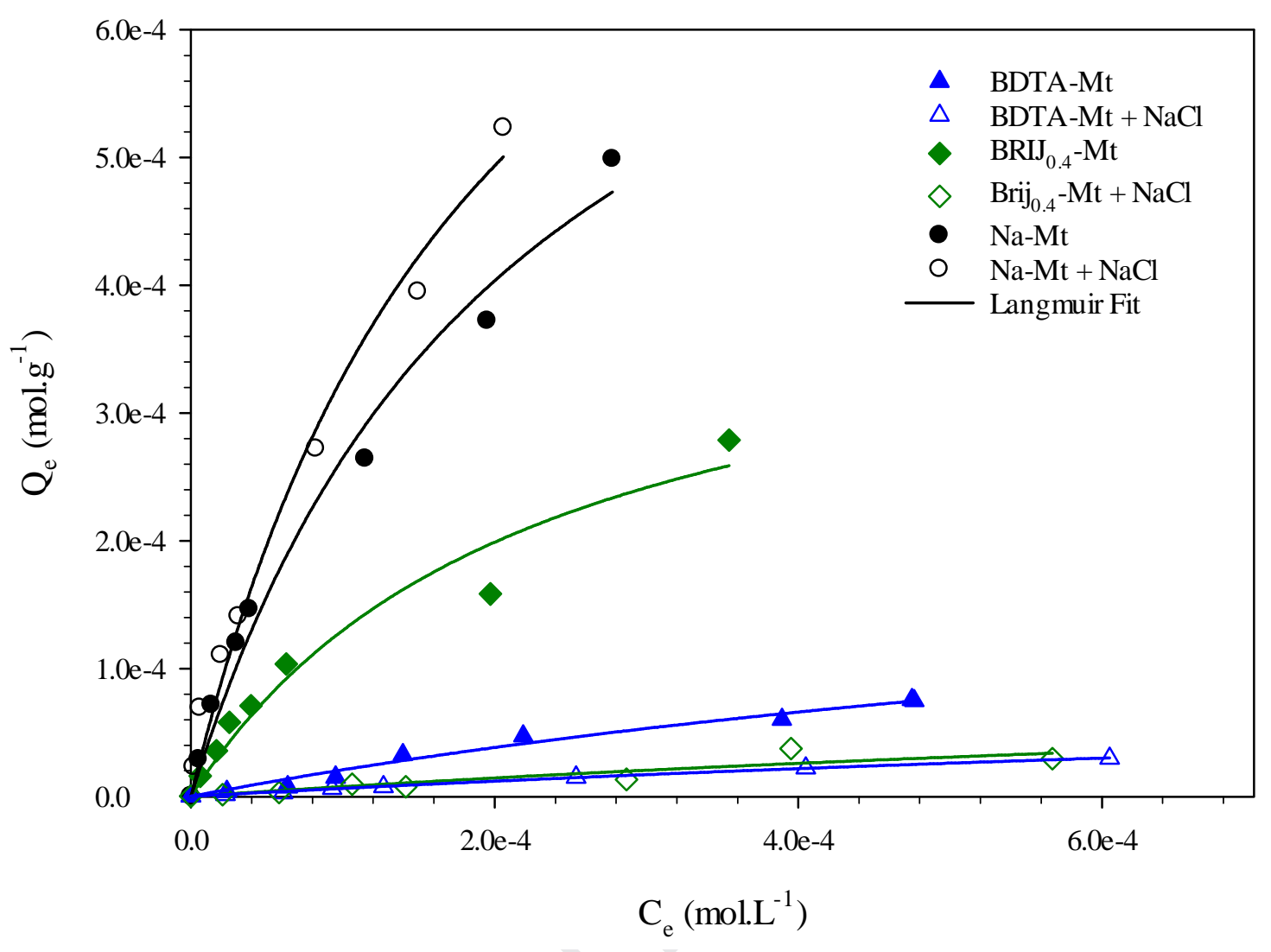

Figure 2e: Effect of the ionic strength with the addition of $\mathrm{NaCl}$ electrolytes $\left(10^{-2} \mathrm{M}\right)$ on the equilibrium adsorption isotherms of Norfloxacin (NFX) onto untreated $\mathrm{Na}$ exchanged montmorillonite: Na-Mt (circle), BDTA-Mt (triangle top) and Brijo.4-Mt (diamond). Q represents the adsorbed amount of pharmaceutical while $\mathrm{C}_{\mathrm{e}}$ is the equilibrium pharmaceutical concentration. The solid lines represent the fits by using the Langmuir equation model. 


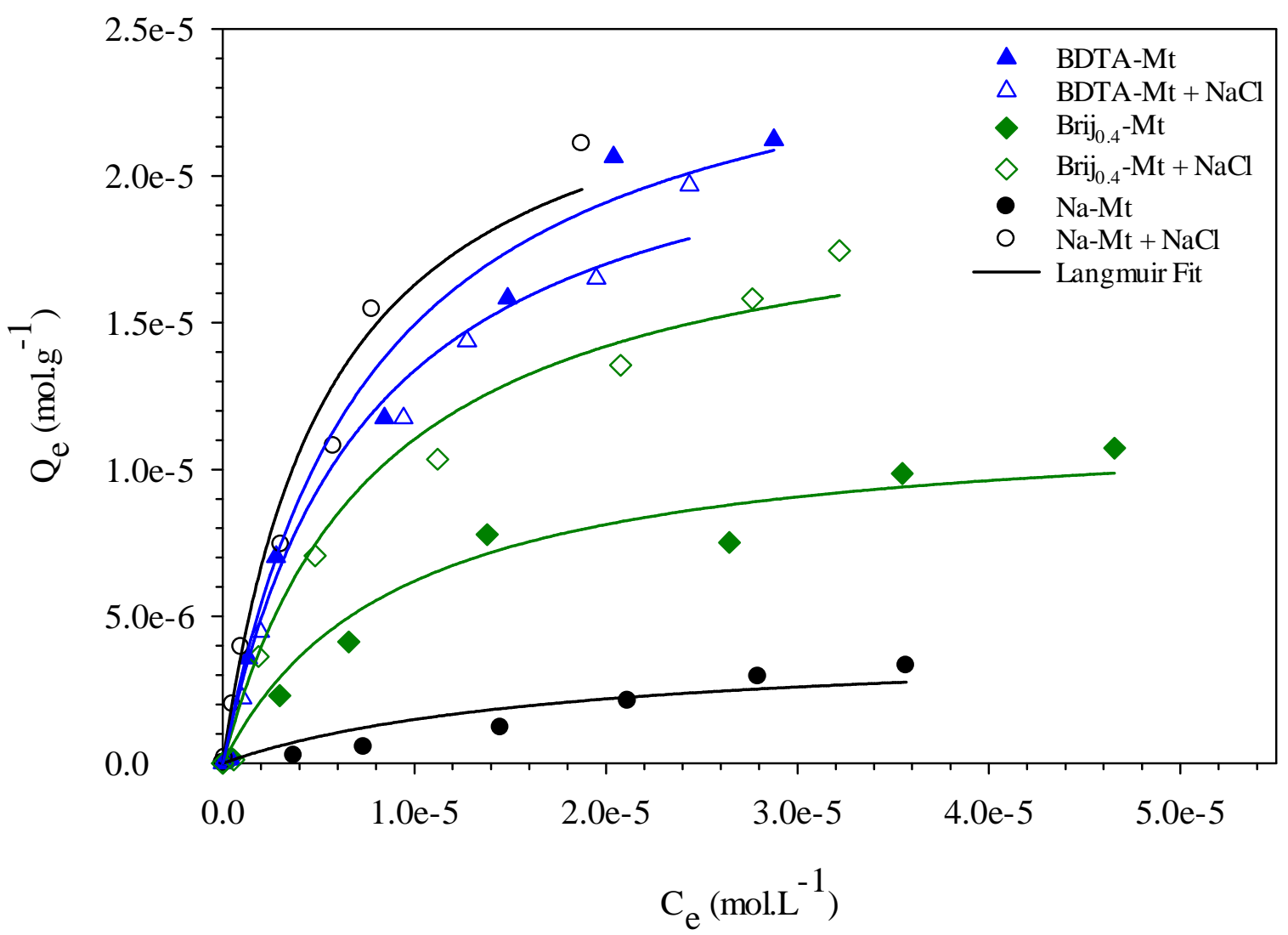

Figure 2f: Effect of the ionic strength with the addition of $\mathrm{NaCl}$ electrolytes $\left(10^{-2} \mathrm{M}\right)$ on the equilibrium adsorption isotherms of Carbamazepine (CBZ) onto untreated $\mathrm{Na}$ exchanged montmorillonite: Na-Mt (circle), BDTA-Mt (triangle top) and Brijo.4-Mt (diamond). $\mathrm{Q}_{\mathrm{e}}$ represents the adsorbed amount of pharmaceutical while $\mathrm{C}_{\mathrm{e}}$ is the equilibrium pharmaceutical concentration. The solid lines represent the fits by using the Langmuir equation model. 


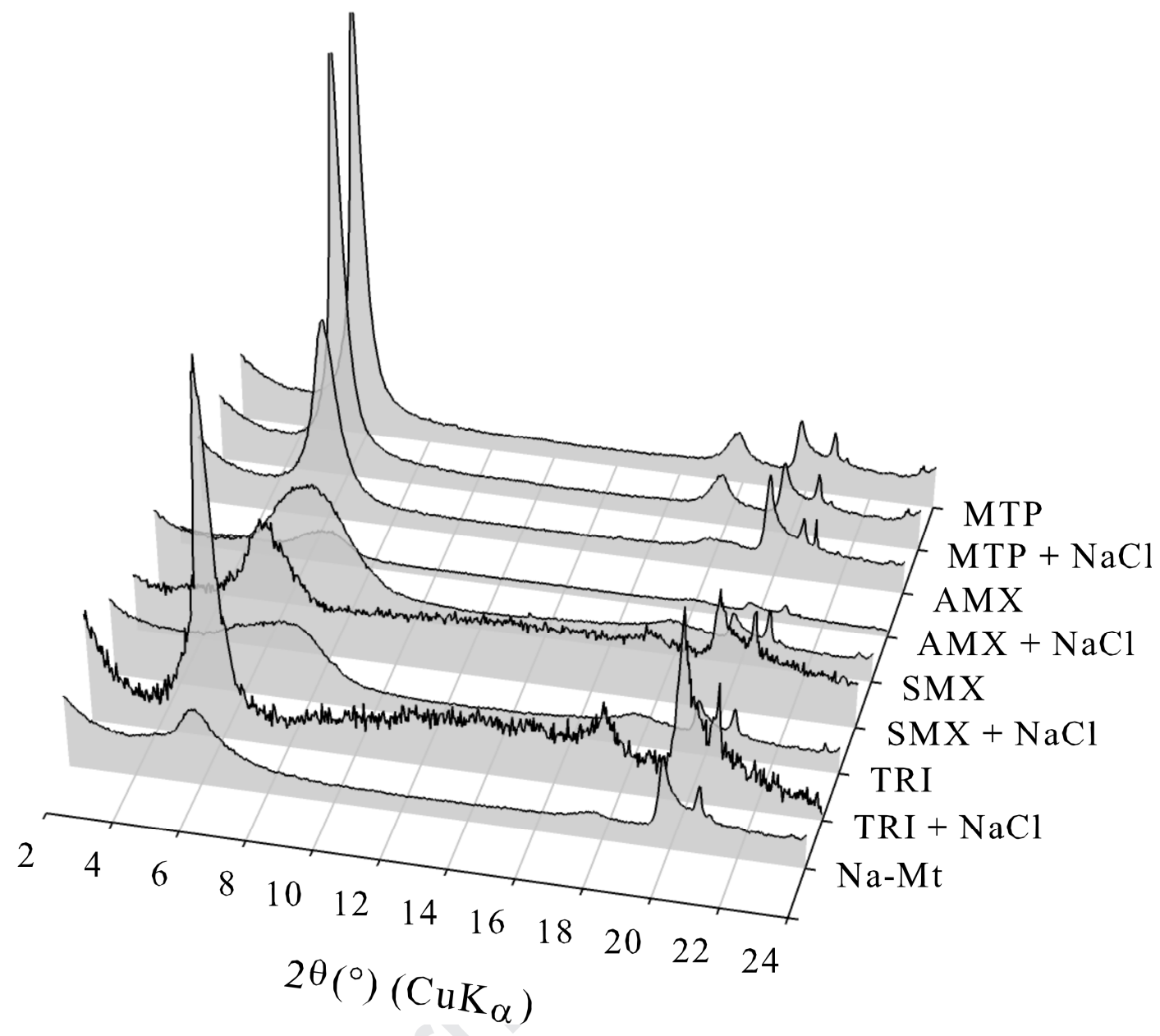

Figure 3: 3D evolution of the X-ray diffraction patterns (selected data) of Na-Mt after the adsorption of Trimethoprim (TRI), Sulfamethoxazole (SMX), Amoxicililin (AMX) and Metropolol (MTP) with and without any electrolytes $\left(\mathrm{NaCl}\right.$ at a concentration of $\left.10^{-2} \mathrm{M}\right)$. With an interlayer distance ( $\mathrm{d}_{001}$ spacing) of about $18 \AA$, and an average molecular size of $5 \AA$ for the pharmaceuticals, no structural changes in the evolution of the organoclays are observed. 


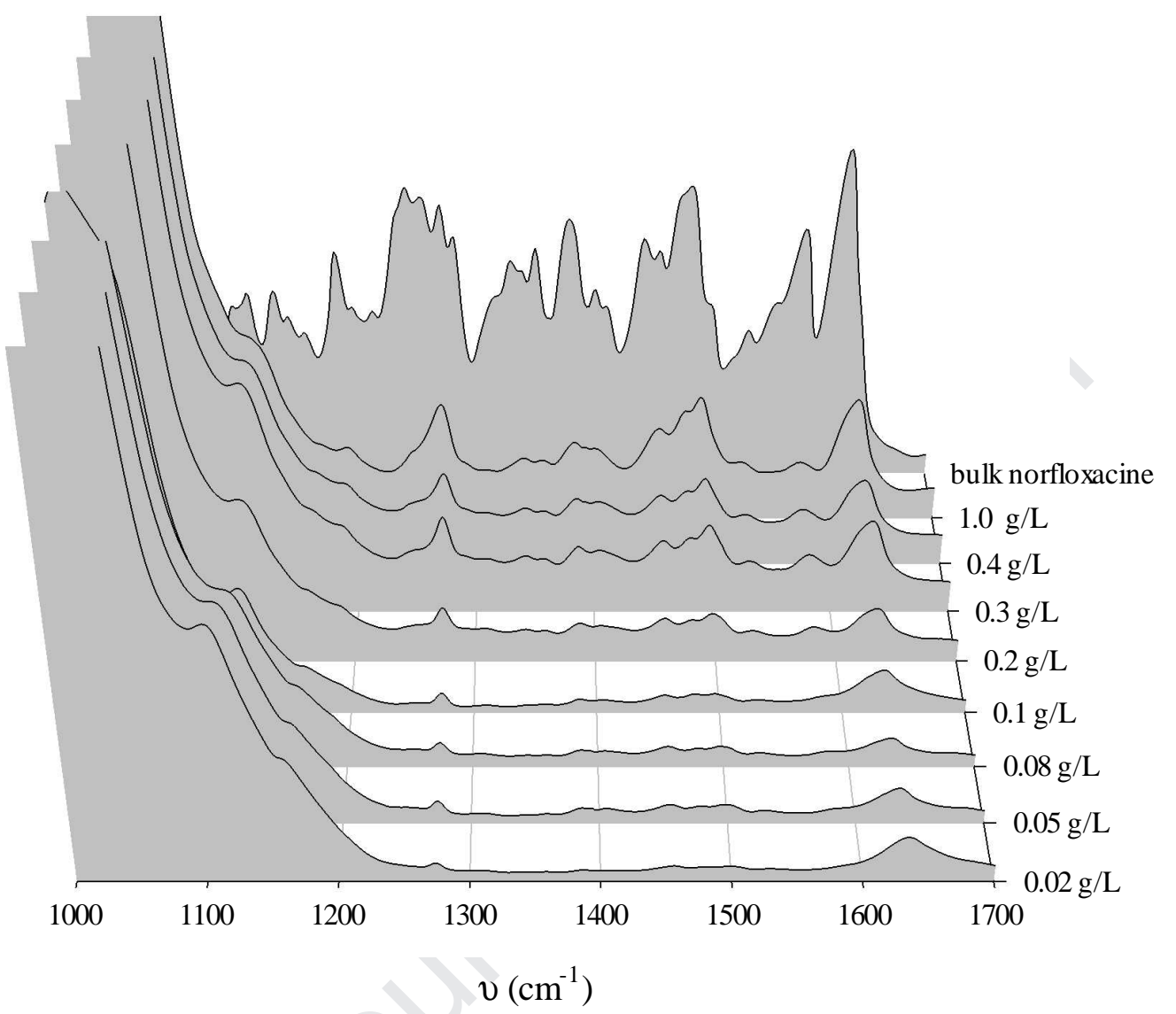

4 Figure 4: 3D evolution of the FTIR spectra in the $1000-1700 \mathrm{~cm}^{-1}$ wavenumbers range 5 (probing the $\mathrm{COO}^{-}$absorption bands of the norfloxacine among others) of Na-Mt (selected 6 series but a similar evolution for the other adsorbents was observed) as a function of the 7 starting norfloxacine concentration $\left(\mathrm{g} \mathrm{L}^{-1}\right)$.

(selected data). 


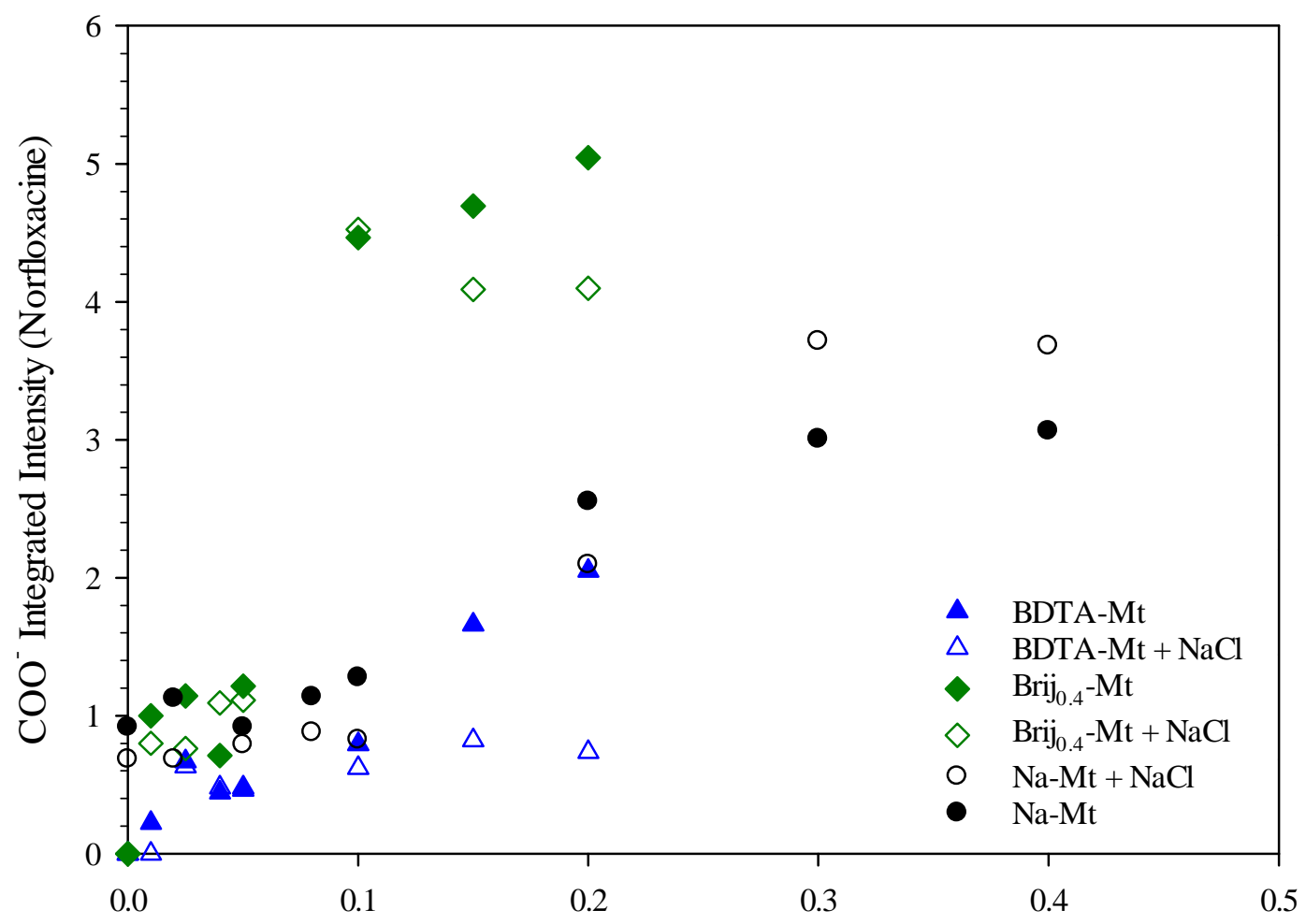

Starting Norfloxacine Concentration $\left(\mathrm{g} \mathrm{L}^{-1}\right)$

17 Figure 5: Integrated intensity of the $\mathrm{COO}^{-}$stretching bands of norfloxacin as a function of the blue and white filled triangle top) cationic organoclay, and Brijo.4-Mt (green and white filled diamond) nonionic organoclay with (symbols filled with a color) and without $\mathrm{NaCl}$ electrolytes. 


\section{Ionic Bridges with $\mathrm{NaCl}$ : Na-Mt Efficiency $\nearrow$}

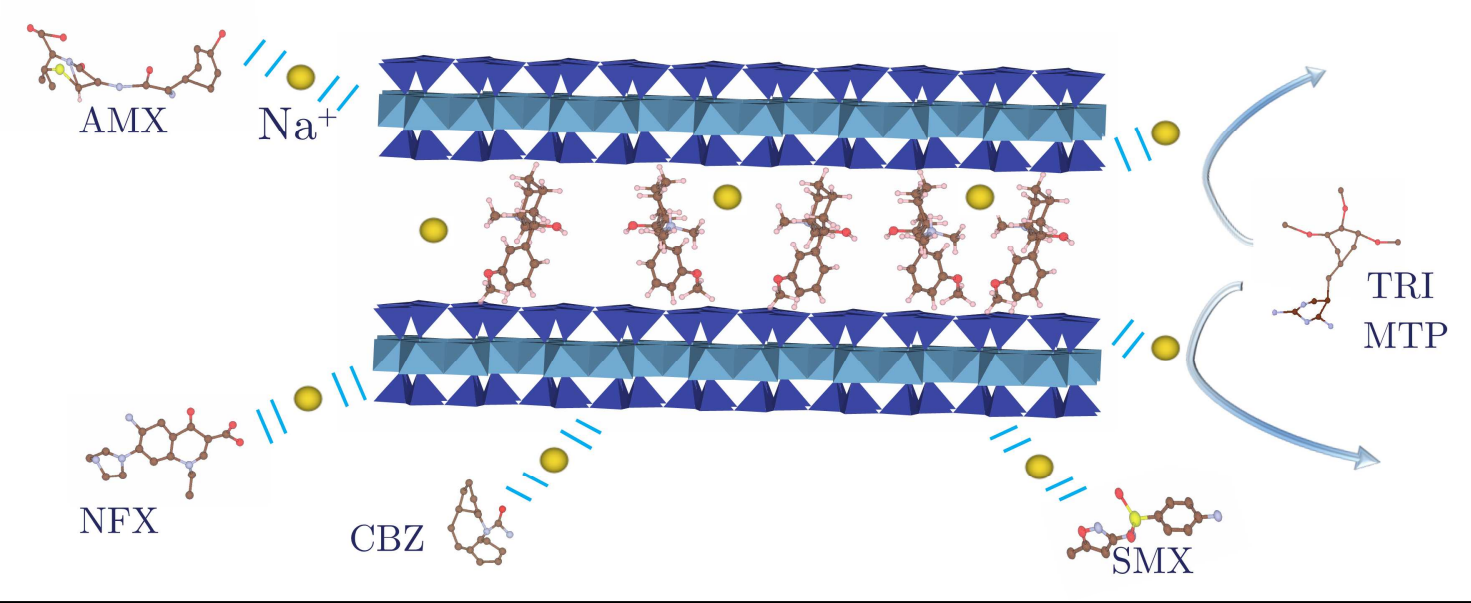

\section{Fall Down of Organoclay Adsorption Properties with Salts}

Figure 6: Schematic representation of the impact of the salts on the adsorption/desorption of the pharmaceuticals onto Na-Mt, Brij ${ }_{0.4}-\mathrm{Mt}$, and BDTA-Mt. The presence of electrolytes favors the adsorption with the creation of ionic bridges to Na-Mt while it backwards the adsorption/desorption equilibrium of pharmaceuticals onto both nonionic and cationic organoclays showing a poor efficiency in experimental conditions close to that of effluents.

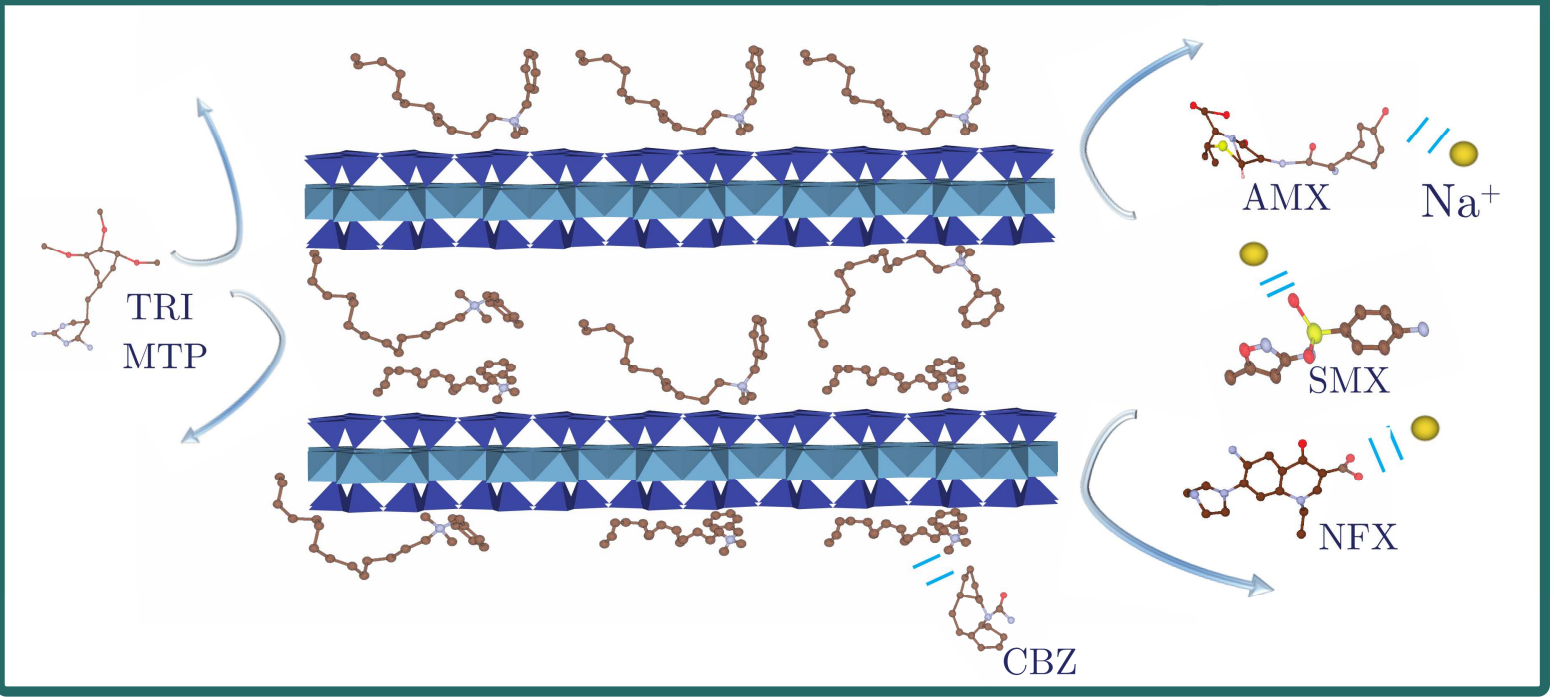

(2) 


\section{Ionic Bridges with $\mathrm{NaCl}$ : Na-Mt Efficiency $\lambda$}

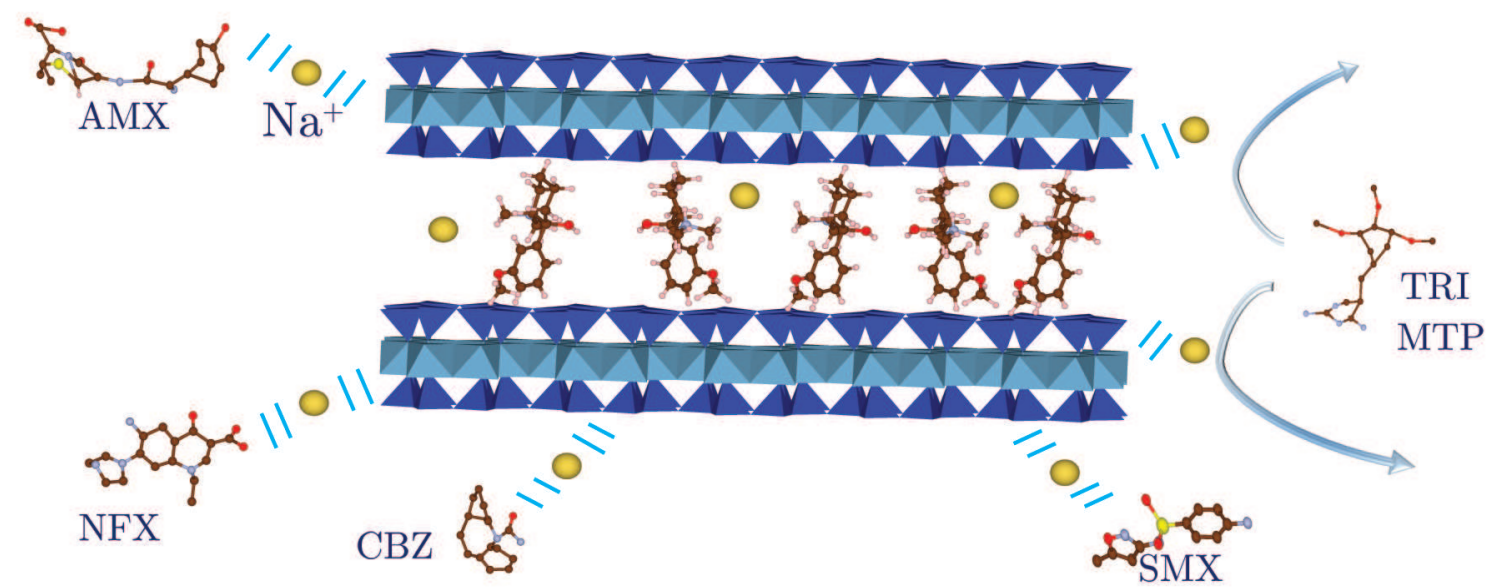

Fall Down of Organoclay Adsorption Properties with Salts

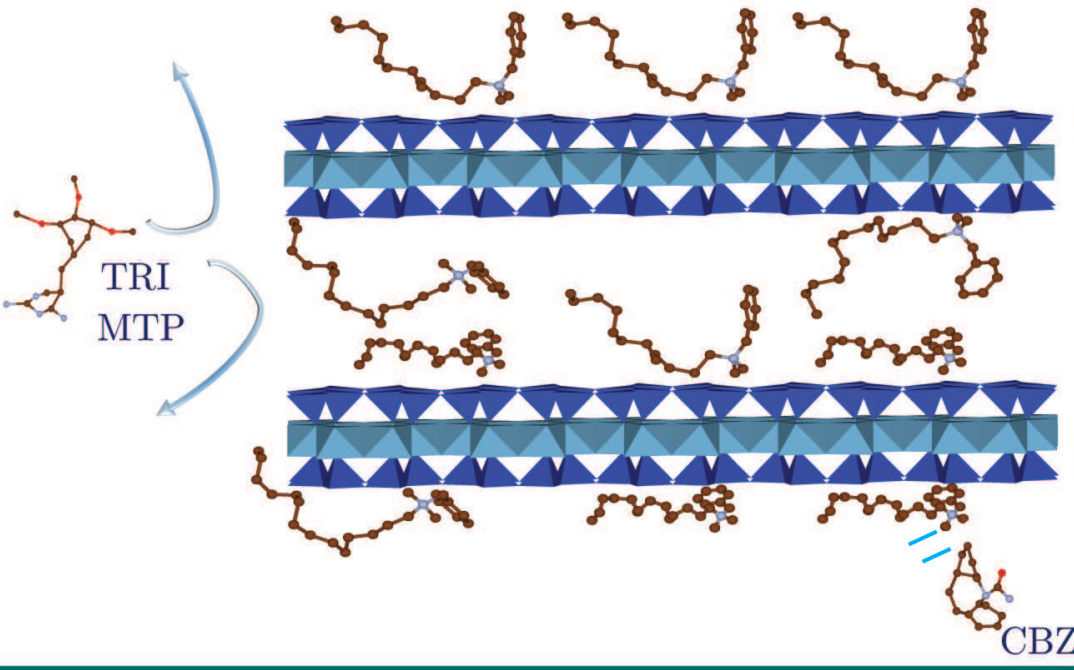

$$
\underset{\mathrm{AMX}}{\mathrm{Na}^{+}}
$$
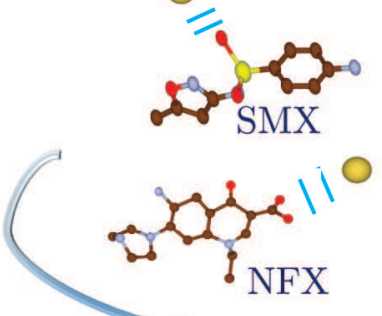


\section{Research Highlights}

The electric charge of pharmaceuticals (PPs) governs their adsorption

Organoclays improve the adsorption of PPs due to their hydrophobic nature

Without any salts, organoclays show a certain efficiency in the adsorption of PPs

The adsorption is enhanced onto Na-Mt in presence of an electrolyte

Organoclays appear as poor sorbent materials in presence of salts 